\title{
Multisite non-invasive brain stimulation in Parkinson's disease: A scoping review
}

\author{
Camila Beatriz da Silva Machado ${ }^{a}$, Letícia Maria da Silva ${ }^{a}$, Alessandra Feitosa Gonçalves ${ }^{b}$, \\ Palloma Rodrigues de Andrade ${ }^{\mathrm{b}}$, Cristina Katya Torres Teixeira Mendes ${ }^{\mathrm{b}}$, \\ Thais Josy Castro Freire de Assis ${ }^{\mathrm{b}}$, Clécio de Oliveira Godeiro Júnior ${ }^{\mathrm{c}, \mathrm{d}}$ \\ and Suellen Marinho Andrade ${ }^{\mathrm{a}, *}$ \\ ${ }^{a}$ Aging and Neuroscience Laboratory, Federal University of Paraiba, João Pessoa, Brazil \\ ${ }^{\mathrm{b}}$ Physical Therapy Department, Federal University of Paraíba, João Pessoa, Brazil \\ ${ }^{\mathrm{c}}$ Division of Neurology, CHU of Grenoble, Grenoble Alpes University, La Tronche, Grenoble, France \\ ${ }^{\mathrm{d}}$ Division of Neurology, Hospital Universitario Onofre Lopes, Federal University of Rio Grande do Norte, Natal, \\ Brazil
}

Received 21 June 2021

Accepted 18 October 2021

\begin{abstract}
.
BACKGROUND: Parkinson's disease (PD) is a progressive neurodegenerative disorder, characterized by cardinal motor symptoms in addition to cognitive impairment. New insights concerning multisite non-invasive brain stimulation effects have been gained, which can now be used to develop innovative treatment approaches.

OBJECTIVE: Map the researchs involving multisite non-invasive brain stimulation in PD, synthesize the available evidence and discuss future directions.

METHODS: The databases PubMed, PsycINFO, CINAHL, LILACS and The Cochrane Library were searched from inception until April 2020, without restrictions on the date of publication or the language in which it was published. The reviewers worked in pairs and sequentially evaluated the titles, abstracts and then the full text of all publications identified as potentially relevant.

RESULTS: Twelve articles met the inclusion criteria. The target brain regions included mainly the combination of a motor and a frontal area, such as stimulation of the primary motor cortex associated with the dorsolateral prefrontal cortex. Most of the trials showed that this modality was only more effective for the motor component, or for the cognitive and/or non-motor, separately.

CONCLUSIONS: Despite the results being encouraging for the use of the multisite aproach, the indication for PD management should be carried out with caution and deserves scientific deepening.

Keywords: Parkinson's disease, non-invasive brain stimulation, transcranial magnetic stimulation, transcranial direct current stimulation
\end{abstract}

\footnotetext{
*Address for correspondence: Suellen Marinho Andrade, PhD., Aging and Neuroscience Laboratory, Physical Therapy Department, Federal University of Paraíba, 58051-900, João Pessoa, PB, Brazil. E-mail: suellenandrade@gmail.com.
} 


\section{Introduction}

Parkinson's disease (PD) is a progressive neurodegenerative disorder, characterized by cardinal motor symptoms such as rigidity, tremor, bradykinesia and postural instability, in addition to non-motor symptoms, such as cognitive impairment (GBD 2016 Parkinson's Disease Collaborators, 2018; Rektorova, 2019). Cardinal motor symptoms of PD reflect the hyperactivity of corticoestriatal glutamatergic transmission and the increased levels of GABA in the striatum (Nieoullon \& Goff, 1992). However, the pathophysiology of cognitive impairment in PD is complex and includes the loss of functional connectivity in the corticosteroidal networks (Ray \& Strafella, 2012), together with the degeneration of dopaminergic, cholinergic and noradrenergic neural systems (Lang \& Obeso, 2004), resulting in impaired executive function, attention and activities of daily living (Litvan et al., 2011). Medical interventions (i.e., antiparkinsonian medication and deep brain stimulation) have important adverse effects and address motor symptoms primarily, while cognitive functions are insufficiently covered (Goldman et al., 2018; Smith et al., 2012). In this context, Non-Invasive Brain Stimulation (NIBS) has been suggested as a therapeutic alternative, with the potential to relieve motor and cognitive symptoms, in addition to minimizing the risks associated with traditional treatment options (Broeder et al., 2015; Chen \& Chen, 2019; Chou et al., 2015; Elsner et al., 2016).

The two most commonly used NIBS techniques for the treatment of PD are repetitive transcranial magnetic stimulation (rTMS) and transcranial direct current stimulation (tDCS) (Benninger \& Hallett, 2015). Both have been shown to induce synaptic plasticity related to long-term potentiation or depression (LTP / LTD) (Esser et al., 2006; Monte-Silva et al., 2013), through different mechanisms. While rTMS is able to promote direct neuronal activation or inhibition, producing action potentials (Pascual-Leone et al., 1994), tDCS induces subliminal neuronal membrane polarization or depolarization (Woods et al., 2016). Changes in cortical networks by NIBS have been reported in previous studies (Hess, 2013; To et al., 2018), however, the dynamic of these effects depends of methodological issues, such as time, electrode montage and stimulation parameters (Deng et al., 2013; Guleyupoglu et al., 2013; Hallett, 2007; Medeiros et al., 2012). In addition, if a network of several cortical areas is responsible for the multiple symptoms referred to in PD (Kalia \& Lang, 2015), stimulation of motor or cognitive regions alone may not be sufficient to achieve effective improvement in these patients (Fregni \& Pascual-Leone, 2007). In this way, new insights concerning multisite neuromodulation effects have been gained, which can now be used to develop innovative treatment approaches (Alagapan et al., 2019; Brown et al., 2019; Fischer et al., 2017).

Although there are promising results involving brain stimulation of multiple targets in PD, there is still no consensus on which therapeutic targets are the most suitable for treatment, nor which regions would be responsible for modifying the disease or just changing the symptoms (Goodwill et al., 2017). Thus, we conducted a systematic scoping review of studies that addressed multisite NIBS effects on motor and cognitive impairments in patients with Parkinson's disease. This work aims to map the researchs carried out in this theme, synthesize the available evidence and discuss future directions, including strategies for enhancing the effects of multisite rTMS and tDCS.

\section{Methods}

\subsection{Study design}

A literature review was systematically carried out describing the use of multisite non-invasive brain stimulation (in particular, rTMS and tDCS) in people with Parkinson's disease. We use as a guide the framework of Arksey and O'Malley (2005) and recommendations based on the work of Levac et al. (2010) and Peters et al. (2015). During the procedures, we followed the guidelines described in the extension of the Preferred Reporting Items for Systematic Reviews and Meta-Analyses for scoping reviews (PRISMA-ScR) (Tricco et al., 2018). The final protocol was registered in the Open Science Framework on June 6th, 2020 (https://osf.io/hyfq8/), according to Preferred Reporting Items for Systematic Review and Meta-Analysis Protocols (PRISMA-P) (Moher et al., 2015).

\subsection{Eligibility criteria}

Studies should meet the following criteria: (1) clinical trials (on manuscript or upon request); (2) non-invasive brain stimulation (TMS and/or tDCS) applied to more than one cortical area; (3) approach to investigate motor-cognitive interplay; (4) participants diagnosed with idiopathic Parkinson's disease. 
Table 1

Search strategy for PubMed

\begin{tabular}{|c|c|c|}
\hline Search & Search term(s) & Results \\
\hline 1 & $\begin{array}{l}\text { ("Parkinson Disease" OR "Idiopathic Parkinson Disease" OR "Idiopathic Parkinson's Disease" OR "Lewy Body } \\
\text { Parkinson Disease" OR “Lewy Body Parkinson's Disease" OR "Paralysis Agitans" OR "Parkinson Disease, } \\
\text { Idiopathic" OR "Parkinson's Disease" OR "Parkinson's Disease, Idiopathic" OR "Parkinson's Disease, Lewy } \\
\text { Body" OR "Parkinsonism, Primary" OR "Primary Parkinsonism" OR "PD" OR "IPD") }\end{array}$ & 120331 \\
\hline 2 & 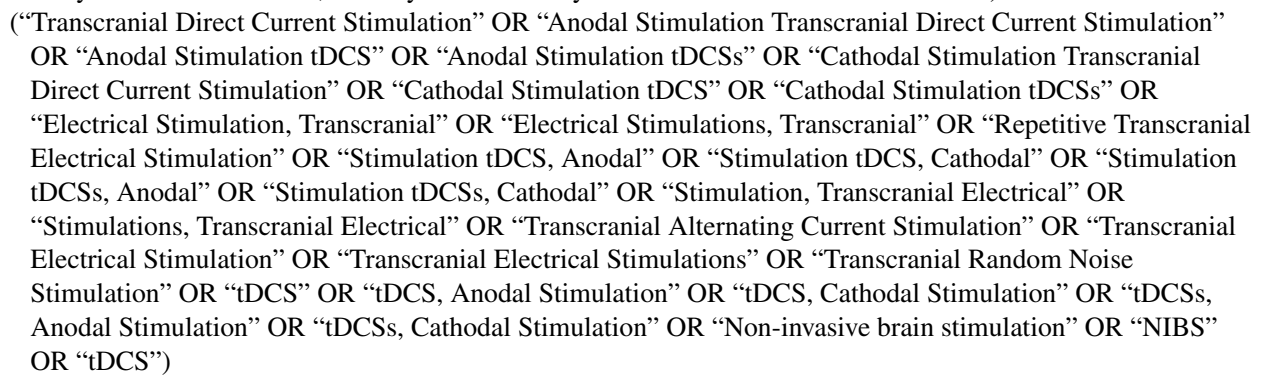 & 5350 \\
\hline 3 & $\begin{array}{l}\text { ("Transcranial Magnetic Stimulation" OR "Magnetic Stimulation, Transcranial” OR "Magnetic Stimulations, } \\
\text { Transcranial” OR "Stimulation, Transcranial Magnetic" OR "Stimulations, Transcranial Magnetic" OR } \\
\text { "Transcranial Magnetic Stimulation, Paired Pulse" OR "Transcranial Magnetic Stimulation, Repetitive" OR } \\
\text { "Transcranial Magnetic Stimulation, Single Pulse" OR "Transcranial Magnetic Stimulations" OR } \\
\text { "Non-invasive brain stimulation" OR "NIBS" OR "TMS” OR "rTMS") }\end{array}$ & 5155 \\
\hline 4 & $\# 1$ AND \#2 & 154 \\
\hline 5 & \#1 AND \#3 & 285 \\
\hline
\end{tabular}

Studies were excluded if they involved: (1) animal studies; (2) bihemispheric stimulation of homologous areas, for example, right and left primary motor cortex; (3) case studies, theoretical simulations and conference abstracts.

\subsection{Sources and search}

The databases PubMed, PsycINFO, CINAHL, LILACS and The Cochrane Library were searched from inception until April 2020, without restrictions on the date of publication or the language in which it was published. The search strategy was based on combinations of terms related to NIBS ('transcranial direct current stimulation', 'tDCS' 'non-invasive brain stimulation', 'transcranial magnetic stimulation', 'TMS', 'rTMS', 'repetitive transcranial magnetic stimulation') and 'Parkinson's disease' from the Medical Subject Headings (MeSH) terms. These were prepared by an experienced librarian and perfected through team discussion. The final search strategy for PubMed can be found in Table 1. The search results were exported into EndNote, and duplicates were removed.

\subsection{Study selection and data extraction}

The screening procedure was carried out independently and blindly by two authors (CM and LS), who sequentially evaluated the titles and abstracts of the studies found in the initial search. If the two evaluators did not reach consensus, a third reviewer (SM) would act as an arbitrator. The full articles of potentially eligible references were retrieved by one of the authors (CM) in electronic format. Their eligibility was then blindly assessed by the same reviewers (CM and LS), using a process similar to that described for screening references.

An Excel spreadsheet and Rayyan, a free online application for systematic review, were used to map the extracted data. The extraction of data from the selected references was performed blindly by the same two authors (CM and LS). Data comparison was carried out, and the differences were discussed as a team in case of disagreement between them.

\subsection{Synthesis of results}

A content analysis of each article was applied and summarized as a table (Tables 2, 3 and 4). The results are described in a narrative way, grouped by the type of intervention (electrical, magnetic stimulation or both), characteristics of the participants, cortical areas targeted by the stimulation, stimulation parameters, outcome measures and main results. 
Table 2

Studies investigating multisite transcranial magnetic stimulation (TMS) as a therapeutic tool in PD

\begin{tabular}{|c|c|c|c|c|c|c|c|c|}
\hline$\overline{\text { Study }}$ & Design & Participants characteristics & Stimulation sites & Coil shape & Stimulation parameters & $\begin{array}{l}\text { No. of pulses and } \\
\text { duration }\end{array}$ & Outcomes measures & Main findings \\
\hline $\begin{array}{l}\text { Aftanas et al. } \\
\text { (2018) }\end{array}$ & $\begin{array}{r}\text { Randomized, parallel } \\
\text { placebo-controlled }\end{array}$ & $\begin{array}{l}\text { Treatment group (real TMS): } \\
N=24 ; \text { Mean } \\
\text { age } \pm \mathrm{SD}=63.2 \pm 1.7 ; \\
\mathrm{M} / \mathrm{F}=13 / 11 \\
\text { Control group (sham TMS): } \\
N=25 ; \text { Mean } \\
\text { age } \pm \mathrm{SD}=63.8 \pm 1.5 ; \\
\mathrm{M} / \mathrm{F}=10 / 15\end{array}$ & $\begin{array}{l}\text { Bilateral M1 and 1-PFC } \\
\text { (dorsolaterally). }\end{array}$ & Not reported & $\begin{array}{l}\text { rTMS, } 100 \%(\mathrm{M} 1) \text { and } \\
110 \%(\mathrm{l}-\mathrm{PFC}) \mathrm{RMT} \\
\mathrm{M} 1: 10 \mathrm{~Hz} / 5 \mathrm{~s} \text { each } \\
\text { train and } 10 \mathrm{~s} \\
\text { intertrain }(\mathrm{M} 1) \text { or } \\
15 \mathrm{~s} \text { intertrain } \\
\text { (1-PFC) } / 20 \mathrm{~min}\end{array}$ & $\begin{array}{l}\text { M1 : } 4000 \text { pulses; } \\
\text { 1-PFC: } 3000 \text { pulses; } \\
20 \text { sessions }\end{array}$ & $\begin{array}{l}\text { Levels of spontaneous } \\
\text { and } \\
\text { mitogen-stimulated } \\
\text { proinflammatory and } \\
\text { anti- } \\
\text { inflammatory } \\
\text { cytokines; BDNF }\end{array}$ & $\begin{array}{l}\text { A positive clinical dynamics } \\
\text { (assessed by UPRS) was } \\
\text { accompanied by a } \\
\text { significant drop in } \\
\text { spontaneous production of } \\
\text { proinflammatory cytokines } \\
\text { However, rTMS produced } \\
\text { no significant effect on } \\
\text { serum BDNF. }\end{array}$ \\
\hline $\begin{array}{l}\text { Benninger et al. } \\
\text { (2011) }\end{array}$ & $\begin{array}{l}\text { Randomized, } \\
\text { double-blind, } \\
\text { sham-controlled }\end{array}$ & $\begin{array}{l}\text { Treatment group (real TMS): } \\
N=13 ; \text { Mean } \\
\text { age } \pm \mathrm{SD}=62.1 \pm 6.9 ; \\
\mathrm{M} / \mathrm{F}=7 / 6 \\
\text { Control group (sham TMS): } \\
N=13 ; \text { Mean } \\
\text { age } \pm \mathrm{SD}=65.6 \pm 9.0 ; \\
\mathrm{M} / \mathrm{F}=11 / 2\end{array}$ & $\begin{array}{l}\text { M1 and DLPFC } \\
\text { bilaterally }\end{array}$ & $\begin{array}{l}\text { Circular 90-mm } \\
\text { coil }\end{array}$ & $\begin{array}{l}\text { iTBS, } 80 \% \text { AMT } \\
\text { Bursts of } 3 \text { pulses at } \\
50 \mathrm{~Hz} \text { repeated at } \\
200 \text {-msec intervals } \\
(5 \mathrm{~Hz}) \text { for } 2 \text { seconds } \\
\text { (10 bursts). These } 2 \mathrm{~s} \\
\text { trains were repeated } \\
20 \text { times every } 10 \mathrm{~s} .\end{array}$ & $\begin{array}{l}2400 \text { pulses/sessions; } 8 \\
\text { sessions }\end{array}$ & $\begin{array}{l}\text { 10MWT; Speed on a } \\
\text { sequential hand and } \\
\text { arm movements; } \\
\text { UPDRS; BDI; } \\
\text { SF-12v2; SRTT; } \\
\text { RMT, AMT and } \\
\text { MEP amplitudes }\end{array}$ & $\begin{array}{l}\text { Beneficial effects of iTBS on } \\
\text { mood, but no improvement } \\
\text { of gait, bradykinesia, } \\
\text { UPDRS, and other } \\
\text { measures. }\end{array}$ \\
\hline $\begin{array}{l}\text { Cohen et al. } \\
\text { (2018) }\end{array}$ & $\begin{array}{l}\text { Randomized, } \\
\text { double-blind, } \\
\text { sham-controlled }\end{array}$ & 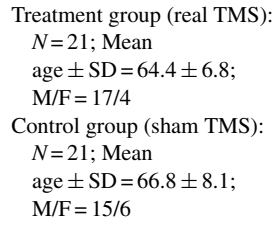 & $\mathrm{M} 1$ and $\mathrm{PFC}$ & $\begin{array}{l}\text { H5 version of } \\
\text { the H-coil }\end{array}$ & $\begin{array}{l}\text { D-rTMS and HF } \\
\text { D-rTMS, } 110 \% \text { (M1) } \\
\text { and } 100 \% \text { (PFC) } \\
\text { RMT } \\
\text { M1 }: 1 \mathrm{~Hz} / 15 \mathrm{~min} \\
\text { PFC: } 10 \mathrm{~Hz} / 2 \mathrm{~s} \text { each } \\
\text { train and } 20 \mathrm{~s} \\
\text { intertrain } / 15 \mathrm{~min}\end{array}$ & $\begin{array}{l}\text { M1 : } 900 \text { pulses; PFC: } \\
800 \text { pulses; } 24 \\
\text { sessions }\end{array}$ & $\begin{array}{l}\text { UPDRS total and motor } \\
\text { UPDRS } \\
\text { TUG test; BDI; DST-F } \\
\text { and DST-B; Word } \\
\text { fluency tests }\end{array}$ & $\begin{array}{l}\text { There was an improvement in } \\
\text { UPDRS over time in both } \\
\text { groups. The analysis of } \\
\text { secondary outcomes did } \\
\text { not reveal a significant } \\
\text { main effect for treatment } \\
\text { for all tasks. }\end{array}$ \\
\hline $\begin{array}{l}\text { Lomarev et al. } \\
\text { (2005) }\end{array}$ & $\begin{array}{l}\text { Pseudorandomized, } \\
\text { double-blind. } \\
\text { placebo-controlled }\end{array}$ & $\begin{array}{l}\text { Treatment group (real TMS): } \\
N=9 ; \text { Mean } \\
\text { age } \pm \mathrm{SD}=63 \pm 10 ; \\
\mathrm{M} / \mathrm{F}=7 / 2 \\
\text { Control group (sham TMS): } \\
N=9 ; \text { Mean } \\
\text { age } \pm \mathrm{SD}=66 \pm 10 ; \\
\mathrm{M} / \mathrm{F}=8 / 1\end{array}$ & $\begin{array}{l}\text { M1 and DLPC, } \\
\text { bilaterally }\end{array}$ & Solid core coil & $\begin{array}{l}\text { rTMS; 100\% RMT; } \\
25 \mathrm{~Hz}\end{array}$ & $\begin{array}{l}1200 \text { pulses/sessions; } 8 \\
\text { sessions }\end{array}$ & $\begin{array}{l}\text { 10MWT; Complex } \\
\text { hand and arm } \\
\text { movement test; } \\
\text { UPDRS; MEP }\end{array}$ & $\begin{array}{l}\text { Improvement of gait and } \\
\text { bradykinesia of the upper } \\
\text { extremities after real } \\
\text { rTMS. Right-hand } \\
\text { bradykinesia improvement } \\
\text { correlated with increased } \\
\text { MEP amplitude evoked by } \\
\text { left MC rTMS after } \\
\text { individual sessions. }\end{array}$ \\
\hline Oh et al. (2015) & $\begin{array}{l}\text { Randomized, } \\
\text { double-blind, } \\
\text { sham-controlled }\end{array}$ & 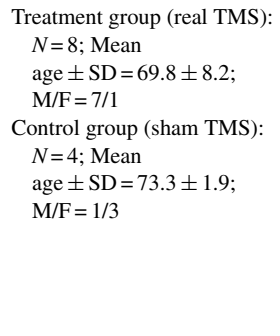 & $\begin{array}{l}\text { M1 and DLPFC } \\
\text { bilaterally }\end{array}$ & Figure-of- 8 coil & $\begin{array}{l}\text { HF-rTMS, } 110 \% \text { RMT, } \\
5 \mathrm{~Hz} / 10 \mathrm{~s} \text { and } \\
\text { interval } 5 \mathrm{~s} \text {. }\end{array}$ & $\begin{array}{l}1200 \text { pulses/sessions; } \\
10 \text { sessions }\end{array}$ & $\begin{array}{l}\text { UPDRS-III; Kinematic } \\
\text { gait analysis; FoG-Q; } \\
\text { K-NMSS; K-PDQ39; } \\
\text { K-MMSE; K-MoCA; } \\
\text { FAB }\end{array}$ & $\begin{array}{l}\text { FoG-Q and UPDRS part III } \\
\text { were improved in real } \\
\text { treatment group and } \\
\text { maintained until } 6 \text { weeks } \\
\text { from the baseline. In } \\
\text { nonmotor symptoms, } \\
\text { K-NMSS and K-PDQ } 39 \\
\text { were improved until } 6 \\
\text { weeks in real treatment } \\
\text { group, however no changes } \\
\text { were shown in cognitive } \\
\text { function test. }\end{array}$ \\
\hline
\end{tabular}




\begin{tabular}{|c|c|c|c|c|c|c|c|c|}
\hline Brys et al. (2016) & $\begin{array}{l}\text { Randomized, } \\
\text { multicenter, } \\
\text { double-blind, } \\
\text { sham-controlled, } \\
\text { parallel-group }\end{array}$ & $\begin{aligned} & \mathrm{G} 1: N=20 ; \text { Mean } \\
& \text { age } \pm \mathrm{SD}=64.9 \pm 8.0 ; \\
& \mathrm{M} / \mathrm{F}=9 / 11 \\
& \mathrm{G} 2: N=14 ; \text { Mean } \\
& \text { age } \pm \mathrm{SD}=59.6 \pm 12.6 ; \\
& \mathrm{M} / \mathrm{F}=5 / 9 \\
& \mathrm{G} 3: N=12 ; \text { Mean } \\
& \text { age } \pm \mathrm{SD}=64.6 \pm 12.3 ; \\
& \mathrm{M} / \mathrm{F}=6 / 6 \\
& \mathrm{G} 4: N=15 ; \text { Mean } \\
& \text { age } \pm \mathrm{SD}=64.0 \pm 7.4 ; \\
& \mathrm{M} / \mathrm{F}=4 / 11\end{aligned}$ & $\begin{array}{l}\text { G1: Bilateral } \\
\text { M1 + 1-DLPFC; G2: } \\
\text { Bilateral M1; G3: } \\
\text { l-DLPFC; G4: } \\
\text { Double sham }\end{array}$ & $\begin{array}{l}\text { Figure-of-eight } \\
\text { coil }\end{array}$ & $\begin{array}{l}\text { rTMS, } 50 \text { trains of } 40 \\
\text { stimuli at } 10 \mathrm{~Hz} \\
\text { (Intensity - NR) }\end{array}$ & $\begin{array}{l}2000 \text { pulses for the left } \\
\text { DLPFC and } 1000 \\
\text { pulses for each M1; } \\
10 \text { sessions }\end{array}$ & $\begin{array}{l}\text { UPDRS-III; HAM-D } \\
\text { and BDI-II; Clinical } \\
\text { Anxiety Scale; MoCA; } \\
\text { Clinical Global } \\
\text { Impression scale; } \\
\text { UPDRS total; } \\
\text { PDQ-39 }\end{array}$ & $\begin{array}{l}\text { Benefit of M1 rTMS for } \\
\text { motor symptoms but no } \\
\text { benefit of left DLPFC } \\
\text { rTMS for mood symptoms, } \\
\text { and not improvement of } \\
\text { combined M1 and } \\
\text { 1-DLPFC rTMS for motor } \\
\text { or mood symptoms. }\end{array}$ \\
\hline $\begin{array}{l}\text { Khedr et al. } \\
(2006)\end{array}$ & $\begin{array}{l}\text { Randomized (partially), } \\
\text { double-blind, } \\
\text { controlled }\end{array}$ & $\begin{array}{l}\text { G1: } N=10 ; \text { Mean } \\
\text { age } \pm \mathrm{SD}=53.5 \pm 11.47 ; \\
\mathrm{M} / \mathrm{F}=\mathrm{NR} \\
\mathrm{G} 2: N=25 ; \text { Mean } \\
\text { age } \pm \mathrm{SD}=62.48 \pm 9.8 ; \\
\mathrm{M} / \mathrm{F}=\mathrm{NR} \\
\mathrm{G} 3: N=10 ; \text { Mean } \\
\text { age } \pm \mathrm{SD}=60.2 \pm 9.48 ; \\
\mathrm{M} / \mathrm{F}=\mathrm{NR} \\
\mathrm{G} 4: N=10 ; \text { Mean } \\
\text { age } \pm \mathrm{SD}=60.6 \pm 10.3 ; \\
\mathrm{M} / \mathrm{F}=\mathrm{NR}\end{array}$ & $\begin{array}{l}\text { G1, } 2 \text { and 3: Motor } \\
\text { lower limbs and } \\
\text { hands area } \\
\text { bilaterally; G4: } \\
\text { Occipital area }\end{array}$ & Figure 8 coil & $\begin{array}{l}\text { rTMS, } 100 \% \text { RMT } \\
\text { G1, } 2 \text { and } 4: 25 \mathrm{~Hz} / 10 \\
\text { trains/ each } 4 \mathrm{~s} \text { and } \\
50 \mathrm{~s} \text { intertrain } \\
\text { G3 }: 10 \mathrm{~Hz} / 20 \text { trains } / 5 \mathrm{~s} \\
\text { and } 50 \mathrm{~s} \text { intertrain. }\end{array}$ & $\begin{array}{l}3000 \text { pulses/sessions; } 6 \\
\text { sessions }\end{array}$ & $\begin{array}{l}\text { UPDRS; Time to walk } \\
25 \text { meters, turn } \\
\text { around and back; } \\
\text { Self- } \\
\text { Assessment Scale; } \\
\text { Keyboard Tapping }\end{array}$ & $\begin{array}{l}\text { Compared to occipital } \\
\text { stimulation, } 25 \mathrm{~Hz} \text { rTMS } \\
\text { over motor areas improved } \\
\text { all measures in both } \\
\text { groups. The group that } \\
\text { received } 10 \mathrm{~Hz} \text { rTMS } \\
\text { improved more than the } \\
\text { occipital group but less } \\
\text { than the } 25 \mathrm{~Hz} \text { groups. }\end{array}$ \\
\hline $\begin{array}{l}\text { Fricke et al. } \\
\text { (2019) }\end{array}$ & $\begin{array}{l}\text { Randomized } \\
\text { (crossover), } \\
\text { double-blind, } \\
\text { sham-controlled }\end{array}$ & $\begin{array}{l}\mathrm{N}=20 ; \text { Mean } \\
\text { age } \pm \mathrm{SD}=58.5 \pm 14.1 \\
\mathrm{M} / \mathrm{F}=15 / 5\end{array}$ & $\begin{array}{l}\text { M1 and PMd of the } \\
\text { hemisphere } \\
\text { corresponding to the } \\
\text { clinically more } \\
\text { impaired body side. }\end{array}$ & $\begin{array}{l}\text { Two custom } \\
\text { built } \\
\text { D-shaped } \\
\text { coils }\end{array}$ & $\begin{array}{l}\text { rTMS, } 95 \% \text { RMT at } \\
\text { each coil } \\
1 \text { Hz / } 40 \text { blocks of } 25 \\
\text { stimuli each } / 5 \mathrm{~s} \\
\text { pause between each } \\
\text { block } / 25 \mathrm{~ms} \\
\text { between premotor } \\
\text { and motor TMS } \\
\text { pulses. }\end{array}$ & $\begin{array}{l}1000 \text { pairs of stimuli; } 1 \\
\text { session }\end{array}$ & $\begin{array}{l}\text { MDS-UPDRS-III; } \\
\text { Finger tapping task; } \\
\text { Triaxial wireless } \\
\text { accelerometers }\end{array}$ & $\begin{array}{l}\text { A single sessions of } \\
\text { ADS-rTMS was tolerated } \\
\text { well, but did not produce a } \\
\text { clinically meaningful } \\
\text { benefit on motor } \\
\text { symptoms. }\end{array}$ \\
\hline $\begin{array}{l}\text { Spagnolo et al. } \\
\text { (2014) }\end{array}$ & Open-label pilot study & $\begin{array}{l}\mathrm{N}=27 ; \text { Mean } \\
\text { age } \pm \mathrm{SD}=60.1 \pm 6.8 \\
\mathrm{M} / \mathrm{F}=20 / 7\end{array}$ & $\begin{array}{l}\text { M1 of the more } \\
\text { affected hemisphere } \\
\text { and PFC bilaterally }\end{array}$ & H-coil & $\begin{array}{l}\text { D-rTMS, 90\% (M1) } \\
\text { and } 100 \% \text { (PFC) } \\
\text { RMT } \\
10 \mathrm{~Hz} \text { (42 trains of } 2 \mathrm{~s} \\
\text { duration, wait time } \\
22 \mathrm{~s} \text { ). }\end{array}$ & $\begin{array}{l}840 \text { pulses/area; } 12 \\
\text { sessions }\end{array}$ & $\begin{array}{l}\text { Vital signs and adverse } \\
\text { events; UPDRS-III }\end{array}$ & $\begin{array}{l}\text { No adverse events were } \\
\text { recorded. Motor UPDRS } \\
\text { significantly improved after } \\
\text { D-rTMS. }\end{array}$ \\
\hline
\end{tabular}

M/F, male/female; rTMS, Repetitive transcranial magnetic stimulation; M1, primary motor cortex; DLPFC, dorsolateral prefrontal cortex; RMT, resting motor treshold; 10MWT, 10 Meter Walk Test; UPDRS, Unified Parkinson's disease rating scale; MC, motor cortex; MEP, motor evoked potential; iTBS, Intermittent theta-burst stimulation; AMT, Active motor threshold; BDI, Beck Depression Inventory; SF-12v2, 12-Item Short-Form Health Survey; SRTT, Serial reaction time task; D-rTMS, Deep repetitive transcranial magnetic stimulation; PFC, Prefrontal Cortex;

UDPRS-III, Unified Parkinson's disease rating scale part III; HF-rTMS, High frequency repetitive transcranial magnetic stimulation; FOG, Freezing of gait; FOG-Q, Freezing of gait questionnaire; K-NMSS, Korean version of non-Motor Symptoms Scale; K-PDQ39, Korean version of Parkinson Disease Questionnaire-39; K-MMSE, Korean version of Mini-Mental Status examination; K-MoCA, Korean version of Montreal Cognitive Assessment; FAB, Frontal assessment battery; NR, Not reported; HAM-D, Hamilton Depression Rating Scale; MoCA, Montreal Cognitive Assessment; PDQ-39, Parkinson Disease Questionnaire-39; 1-DLPF, left dorsolateral prefrontal cortex; TUG, Timed Up and Go; Digit span test - foward; DST-B, Digit span test - backward; 1-PFC, left prefrontal cortex; BDNF, Brain-derived neurotrophic fator; PMd, dorsal premotor cortex; MDS-UPDRS-III, Movement Disorder Society-sponsored revision of the Unified Parkinson's Disease Rating Scale part III; ADS-rTMS, Associative dual-site repetitive transcranial magnetic stimulation. 
Table 3

Studies investigating multisite transcranial direct current stimulation (tDCS) as a therapeutic tool in PD

\begin{tabular}{|c|c|c|c|c|c|c|}
\hline Study & Design & $\begin{array}{c}\text { Participants } \\
\text { characteristics }\end{array}$ & $\begin{array}{l}\text { Stimulation sites and } \\
\text { polarities }\end{array}$ & Stimulation parameters & Outcomes measures & Main findings \\
\hline $\begin{array}{l}\text { Benninger et al. } \\
\text { (2010) }\end{array}$ & $\begin{array}{l}\text { Randomized, } \\
\text { double-blind, } \\
\text { sham-controlled }\end{array}$ & $\begin{array}{l}\text { Treatment group (real } \\
\text { tDCS): } N=13 ; \text { Mean } \\
\text { age } \pm \mathrm{SD}=63.6 \pm 9.0 ; \\
\mathrm{M} / \mathrm{F}=9 / 4 \\
\text { Control group (sham } \\
\text { tDCS): } N=12 ; \text { Mean } \\
\text { age } \pm \mathrm{SD}=64.2 \pm 8.8 ; \\
\mathrm{M} / \mathrm{F}=7 / 5\end{array}$ & $\begin{array}{l}\text { Anode: Motor and PFC } \\
\text { (alternately) } \\
\text { Cathode: Mastoids }\end{array}$ & $\begin{array}{l}2 \mathrm{~mA}, 20 \mathrm{~m}, 8 \text { sessions, } \\
\text { Anode: } 24.5 \mathrm{~cm}^{2} \\
\text { Cathode: } 25 \mathrm{~cm}^{2}\end{array}$ & $\begin{array}{l}\text { 10MWT; Sequential } \\
\text { hand and arm } \\
\text { movements; UPDRS; } \\
\text { SRTT; BDI; SF-12v2; } \\
\text { Self-assessment of } \\
\text { mobility }\end{array}$ & $\begin{array}{l}\text { Improvement of some gait } \\
\text { parameters for a short time and } \\
\text { of bradykinesia for a longer ( } 3 \\
\text { months). Others measures did } \\
\text { not differ between the tDCS } \\
\text { and sham interventions. }\end{array}$ \\
\hline $\begin{array}{l}\text { Dagan et al. } \\
\text { (2018) }\end{array}$ & $\begin{array}{l}\text { Randomized } \\
\text { (crossover), } \\
\text { double-blind, } \\
\text { sham-controlled }\end{array}$ & $\begin{array}{l}\mathrm{N}=20 ; \text { Mean } \\
\text { age } \pm \mathrm{SD}=68.8 \pm 6.8 \\
\mathrm{M} / \mathrm{F}=17 / 3\end{array}$ & $\begin{array}{l}\text { Anode: 1-DLPFC and M1 } \\
\text { / Only M1 } \\
\text { Cathode: NA* }\end{array}$ & $\begin{array}{l}20 \mathrm{~m}, 2 \text { sessions } \\
\text { (intensity and polarity } \\
-\mathrm{NA}^{*} \text { ) }\end{array}$ & $\begin{array}{l}\text { FOG-provoking test; } \\
\text { TUG test; Stroop test }\end{array}$ & $\begin{array}{l}\text { Performance on the } \\
\text { FOG-provoking Test, TUG } \\
\text { and the Stroop test improved } \\
\text { after simultaneous stimulation } \\
\text { of the M1 and lDLPC, but not } \\
\text { after M1 only or sham } \\
\text { stimulation. }\end{array}$ \\
\hline
\end{tabular}

M/F, male/female; PFC, Prefrontal Cortex; 10MWT, 10 Meter Walk Test; UL, Upper limb; UPDRS, Unified Parkinson's disease rating scale; SRTT, Serial reaction time task; BDI, Beck Depression Inventory; SF-12v2, 12-Item Short-Form Health Survey; 1-DLPF, left dorsolateral prefrontal cortex; M1, primary motor cortex; NA*, Not applicable - HD-tDCS; FOG, Freezing of gait; TUG, Timed Up and Go.

Table 4

Studies investigating multisite rTMS plus tDCS as a therapeutic tool in PD

\begin{tabular}{|c|c|c|c|c|c|c|c|}
\hline Study & Design & $\begin{array}{c}\text { Participants } \\
\text { characteristics }\end{array}$ & Stimulation sites & rTMS protocol & tDCS protocol & Outcomes measures & Main findings \\
\hline $\begin{array}{l}\text { Chang et al. } \\
\text { (2017) }\end{array}$ & $\begin{array}{l}\text { Randomized, } \\
\text { double-blind, } \\
\text { controlled }\end{array}$ & $\begin{array}{l}\text { Dual-mode group: } \\
N=16 ; \text { Mean } \\
\text { age } \pm \mathrm{SD}=63.6 \pm \\
7.5 ; \mathrm{M} / \mathrm{F}=9 / 7 \\
\text { Only rTMS group: } \\
N=16 ; \text { Mean } \\
\text { age } \pm \mathrm{SD}=63.8 \pm 8.3 ; \\
\mathrm{M} / \mathrm{F}=11 / 5\end{array}$ & $\begin{array}{l}\text { HF-rTMS: M1-LL } \\
\text { tDCS: 1-DLPFC }\end{array}$ & $\begin{array}{l}\text { Frequency: } 20 \text { trains } \\
\text { of } 10 \mathrm{~Hz}, 5 \mathrm{~s} \text { each, } \\
55 \mathrm{~s} \text { intertrain } \\
\text { Intensity: } 90 \% \\
\text { (RMT) } \\
\text { Pulses: } 1000 \text { pulses / } \\
\text { sessions } \\
\text { Coil shape: doble } \\
\text { cone coil }\end{array}$ & $\begin{array}{l}\text { Intensity: } 1 \mathrm{~mA} \\
\text { Electrode size: } \\
\text { Anode }-25 \mathrm{~cm}^{2} \text {, } \\
\text { Cathode }-\mathrm{NR} \\
\text { Duration: } 20 \mathrm{~m}, 5 \\
\text { sessions }\end{array}$ & $\begin{array}{l}\text { FOG-Q and modified } \\
\text { Standing-start } 180^{\circ} \\
\text { Turn Test; } \\
\text { UPDRS-III; TUG } \\
\text { test; DST-F and } \\
\text { DST-B; TMT-B; } \\
\text { K-MoCA; GDSSF; } \\
\text { RMT and MEP } \\
\text { amplitude }\end{array}$ & $\begin{array}{l}\text { Significant changes were } \\
\text { observed in FOG, motor } \\
\text { function, and ambulatory } \\
\text { function in both groups. } \\
\text { Executive function showed } \\
\text { significant improvement } \\
\text { after NIBS only in the } \\
\text { dual-mode group. }\end{array}$ \\
\hline
\end{tabular}

M/F, male/female; rTMS, Repetitive transcranial magnetic stimulation; HF, high frequency; M1, primary motor cortex; LL, lower limb; 1-DLPF, left dorsolateral prefrontal cortex; RMT, resting motor threshold; NR, not reported; FOG, Freezing of gait; FOG-Q, Freezing of gait questionnaire; UDPRS-III, Unified Parkinson's disease rating scale part III; TUG, Timed Up and Go; DST-F, Digit span test - foward; DST-B, Digit span test - backward; TMT-B, Trail making test - B; K-MoCA, Korean version of the Montreal Cognitive Assessment; GDSSF, Geriatric Depression Scale Short Form; MEP, Motor evoked potential; NIBS, Non-invasive brain stimulation. 


\subsection{Quality assessment}

Although the use of quality assessment in scoping reviews is little explored, we decided to carry out this step, based on the fact that the assessment of the effectiveness of an intervention can be limited if the quality of the research in question is not addressed. We chose to use the Downs and Black Checklist for Quality Assessment as a method (Downs \& Black, 1998). This checklist includes 27 criteria, which address quality, external and internal validity and power. In this version, we adapted item 27 regarding the power of the study, classifying whether the study performed the power calculation or not. Thus, the maximum score for item 27 was 1 (there was a power analysis) instead of 5 . The final score ranges from 0 to 28 , with higher scores indicating a better methodological quality of the study. The following cut-off points were suggested to categorize studies by quality: excellent $(26-28)$, good (20-25), fair $(15-19)$ and poor $(<14)$ (Hooper et al., 2008). The quality of each included study was independently assessed by two reviewers, with discrepancies resolved through discussion and consensus. The result of the assessment of each of the articles will be presented in a table.

\section{Results}

Figure 1 shows the flowchart of study. The database search identified 1058 potential articles for inclusion. After removing duplicates, 761 articles remained. The title and abstract of each article were screened and 39 articles were identified for full text screening. Finally, 12 articles met the inclusion criteria and were included. The parameters and protocol details of the studies are presented in Tables 2, 3 and 4. Additionally, a quality rating of all studies included in the present review was conducted (Table 5). The interventions evaluated in this scoping review were grouped into following categories: rTMS or tDCS isolated studies and rTMS plus tDCS studies.

\subsection{Trials using multisite transcranial magnetic stimulation (TMS) in Parkinson's disease}

Among the studies included in this review, twelve of them used rTMS as a therapeutic intervention. Table 2 summarizes the characteristics of these studies. Five studies compared only one real condition with a simulated control (Aftanas et al., 2018; Benninger et al., 2011; Cohen et al., 2018; Lomarev et al.,
2006; Oh et al., 2015), two studies compared different intervention paradigms (areas or stimulation parameters) (Brys et al., 2016; Khedr et al., 2006), one study used a cross-sectional design with participants receiving simulated conditions and treatment at random (Fricke et al., 2019), and one study compared the same group before and after the intervention (Spagnolo et al., 2014). Most studies used UK Brain Bank criteria to diagnose Parkinson's disease (Aftanas et al., 2018; Benninger et al., 2011; Brys et al., 2016; Cohen et al., 2018; Khedr et al., 2006; Lomarev et al., 2006; Oh et al., 2015), two others did not report this information (Fricke et al., 2019; Spagnolo et al., 2014). Stages between 2 to 4 on the Hoehn and Yahr Scale were considered as inclusion criteria in many of the articles (Benninger et al., 2011; Brys et al., 2016; Cohen et al., 2018; Lomarev et al., 2006; Oh et al., 2015), while the others varied between 1 to 3 (Fricke et al., 2019), 2 to 3 (Aftanas et al., 2018), and one of these also included all stages (Khedr et al., 2006).

The target brain regions included mainly the combination of a motor and a frontal area, such as stimulation of the primary motor cortex (M1) associated with the dorsolateral prefrontal cortex (DLPFC) or prefrontal cortex (PFC) (Aftanas et al., 2018; Benninger et al., 2011; Brys et al., 2016; Cohen et al., 2018; Lomarev et al., 2006; Oh et al., 2015; Spagnolo et al., 2014). Other studies have focused on the association of two motor areas, equivalent to upper and lower limbs (Khedr et al., 2006), or on the primary motor cortex and the dorsal premotor cortex (Fricke et al., 2019). Few studies report in detail how they located neurostimulation targets. Three studies indicate that they used neuronavigation guided by magnetic resonance (Aftanas et al., 2018; Fricke et al., 2019; Oh et al., 2015), the others describe only how the ideal hotspot was located through the motor evoked potentials (MEP) of the abductor pollicis muscle. For stimulation of the prefrontal region, some moved the coil to $5 \mathrm{~cm}$ in front of the M1 hotspot (Benninger et al., 2011; Brys et al., 2016; Lomarev et al., 2006), and $5.5 \mathrm{~cm}$ (Cohen et al., 2018) or $6 \mathrm{~cm}$ (Spagnolo et al., 2014).

The stimulation parameters of rTMS (including coil shape, intensity, frequency, duration and number of sessions) varied considerably between protocols. Most studies used the traditional form of rTMS, with some variants such as intermittent, high-frequency and deep stimulation. Regarding the number of sessions, protocols with few sessions (1 to 10 sessions) were more frequent than those with longer follow-up (from 20 sessions). 


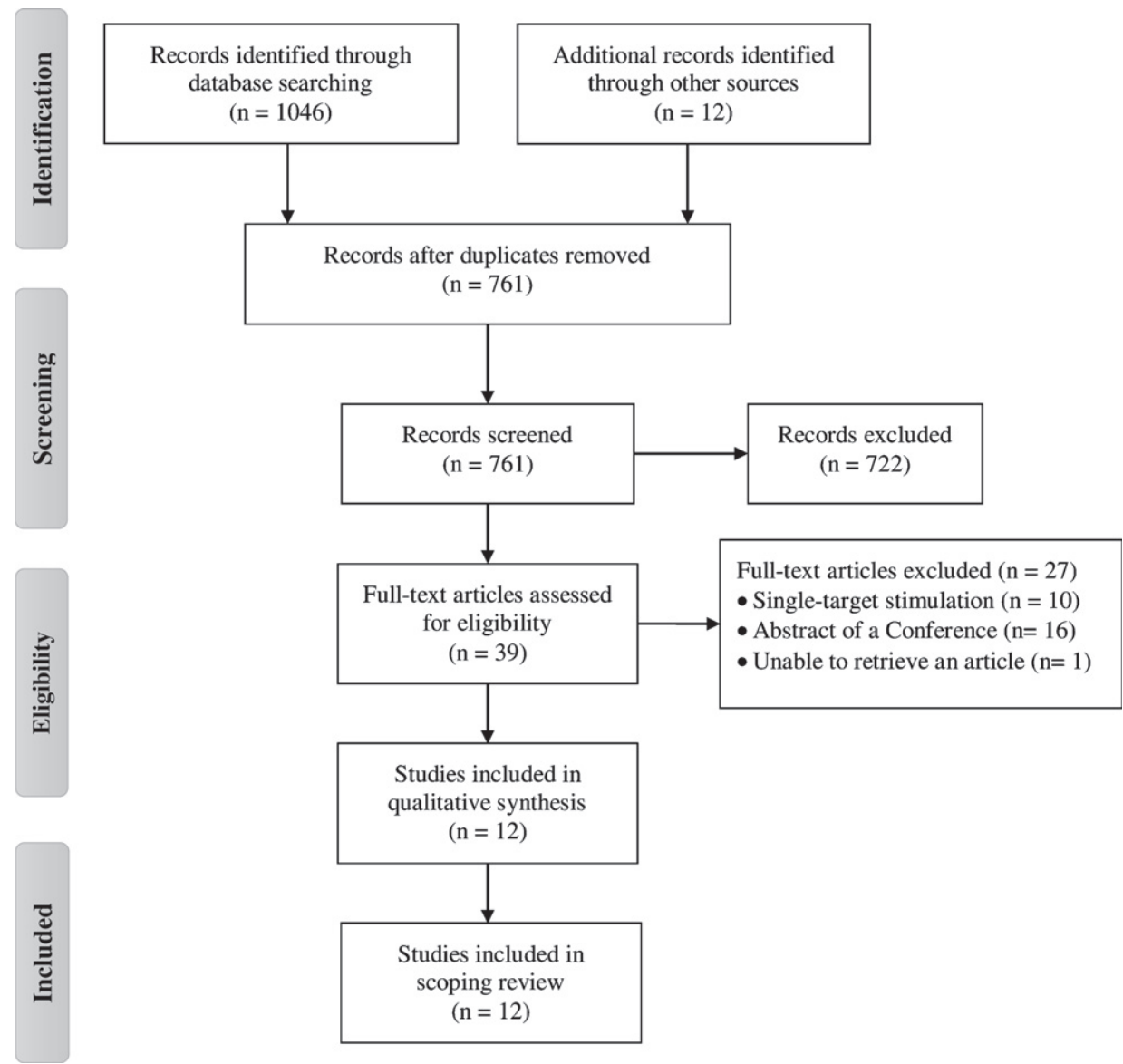

Fig. 1. PRISMA flow diagram of the selection process for the inclusion of the papers.

Cognitive outcomes included visual motor speed and procedural learning, depressive and anxiety symptoms, global cognition, memory, verbal fluency, non-motor symptoms related to PD, executive functions. Motor measurements included gait, bradykinesia, motor function, upper and lower limbs speed, freezing gait and tremor. Some articles used neurophysiological measures such as cortical excitability (MEP, RMT, AMT) and even some specific ones such as the brain-derived neurotrophic factor (BDNF) and blood level of pro-inflammatory and anti-inflammatory cytokines. In general, we found variation in the influence of multisite neuromodulation for the analyzed outcomes. Some of the studies demonstrated benefits for motor outcomes (Khedr et al., 2006; Lomarev et al., 2006; Oh et al., 2015; Spagnolo et al., 2014), and there are also other studies that showed only changes in mood (Benninger et al., 2011) or decreased production of pro-inflammatory cytokines (Aftanas et al., 2018), while some did not demonstrate superiority of this modality for any of the analyzed outcomes (Brys et al., 2016; Cohen et al., 2018; Fricke et al., 2019).

\subsection{Trials using multisite transcranial direct current stimulation (tDCS) in Parkinson's disease}

Two articles were found using only tDCS in more than one therapeutic target (Table 3 ). The study conducted by Benninger et al. (2010) is a parallel trial (sham and active), which the stage of PD was considered as an inclusion criterion, with those with stages between 2 and 4 on the Hoehn and Yahr scale being accepted, mensured in the off state of the medication. However, this was evaluated in the off and on condition, and included as a clinical outcome. Dagan et al. (2018) conducted a crossover study (multitarget, only M1, sham), which the stage was only included in the clinical evaluation. Both report using the UK Brain Bank criteria for diagnose idiopathic PD. 
Table 5

Downs and Black checklist for quality assessment of included studies

\begin{tabular}{|c|c|c|c|c|c|c|c|c|c|c|c|c|}
\hline & $\begin{array}{c}\text { Aftanas } \\
\text { et al. } \\
(2018)\end{array}$ & $\begin{array}{c}\text { Benninger } \\
\text { et al. } \\
(2011) \\
\end{array}$ & $\begin{array}{l}\text { Cohen } \\
\text { et al. } \\
(2018) \\
\end{array}$ & $\begin{array}{c}\text { Lomarev } \\
\text { et al. } \\
(2006)\end{array}$ & $\begin{array}{c}\text { Oh } \\
\text { et al. } \\
(2015) \\
\end{array}$ & $\begin{array}{l}\text { Brys } \\
\text { et al. } \\
(2016) \\
\end{array}$ & $\begin{array}{l}\text { Khedr } \\
\text { et al. } \\
(2006)\end{array}$ & $\begin{array}{l}\text { Fricke } \\
\text { et al. } \\
(2019) \\
\end{array}$ & $\begin{array}{c}\text { Spagnolo } \\
\text { et al. } \\
(2014)\end{array}$ & $\begin{array}{c}\text { Benninger } \\
\text { et al. } \\
(2010)\end{array}$ & $\begin{array}{l}\text { Dagan } \\
\text { et al. } \\
(2018) \\
\end{array}$ & $\begin{array}{l}\text { Chang } \\
\text { et al. } \\
(2017) \\
\end{array}$ \\
\hline \multicolumn{13}{|l|}{ REPORTING } \\
\hline Q1 - Hypothesis/aim/objective clearly described & Yes -1 & Yes -1 & Yes -1 & Yes -1 & Yes -1 & Yes -1 & No -0 & Yes -1 & Yes -1 & Yes -1 & Yes -1 & Yes -1 \\
\hline Q2 - Main outcomes in Introduction or Methods & Yes -1 & Yes -1 & Yes -1 & Yes -1 & Yes -1 & Yes -1 & Yes -1 & & & & & Yes -1 \\
\hline Q3 - Patient characteristics clearly described & Yes -1 & Yes -1 & Yes -1 & Yes -1 & Yes -1 & Yes -1 & Yes -1 & & No -0 & & & Yes -1 \\
\hline Q4 - Interventions of interest clearly described & Yes -1 & Yes -1 & Yes -1 & Yes -1 & Yes -1 & Yes -1 & Yes -1 & Yes -1 & Yes -1 & Yes -1 & Yes -1 & Yes -1 \\
\hline Q5 - Principal confounders clearly described & Partly -1 & Partly - 1 & Partly -1 & Partly - 1 & Yes -1 & Partly - 1 & Partly - 1 & Partly - 1 & No -0 & Partly - 1 & Partly -1 & Partly -1 \\
\hline Q6 - Main findings clearly described & Yes - 1 & Yes -1 & Yes -1 & Yes -1 & Yes -1 & Yes -1 & Yes -1 & Yes -1 & Yes -1 & Yes -1 & Yes -1 & Yes -1 \\
\hline Q7 - Estimates of random variability for main outcomes & Yes -1 & Yes -1 & Yes -1 & Yes -1 & Yes -1 & Yes -1 & Yes -1 & Yes -1 & Yes -1 & Yes -1 & & Yes -1 \\
\hline Q8 - All adverse events of intervention reported & No -0 & Yes -1 & Yes -1 & No -0 & Yes -1 & Yes -1 & Yes -1 & Yes -1 & & & & Yes -1 \\
\hline Q9 - Characteristics of patients lost to follow-up & Yes -1 & Yes -1 & Yes -1 & Yes -1 & Yes -1 & Yes -1 & Yes -1 & Yes -1 & & & & Yes -1 \\
\hline $\begin{array}{l}\text { Q10 - Probability values reported for main outcomes } \\
\text { EXTERNAL VALIDITY }\end{array}$ & No -0 & Yes -1 & Yes -1 & Yes -1 & Yes -1 & No -0 & Yes -1 & Yes -1 & & & & Yes -1 \\
\hline $\begin{array}{l}\text { Q11 - Subjects asked to participate were representative of } \\
\text { source population }\end{array}$ & $\mathrm{UTD}-0$ & $\mathrm{UTD}-0$ & $\mathrm{UTD}-0$ & $\mathrm{UTD}-0$ & $\mathrm{UTD}-0$ & UTD -0 & $\mathrm{UTD}-0$ & $\mathrm{UTD}-0$ & $\mathrm{UTD}-0$ & UTD -0 & $\mathrm{UTD}-0$ & UTD -0 \\
\hline $\begin{array}{l}\text { Q12 - Subjects prepared to participate were representative } \\
\text { of source population }\end{array}$ & $\mathrm{UTD}-0$ & $\mathrm{UTD}-0$ & UTD - 0 & $\mathrm{UTD}-0$ & $\mathrm{UTD}-0$ & UTD -0 & $\mathrm{UTD}-0$ & $\mathrm{UTD}-0$ & $\mathrm{UTD}-0$ & $\mathrm{UTD}-0$ & $\mathrm{UTD}-0$ & $\mathrm{UTD}-0$ \\
\hline $\begin{array}{l}\text { Q13 - Staff/places/facilities study treatment was } \\
\text { representative of source population }\end{array}$ & No -0 & UTD -0 & $\mathrm{UTD}-0$ & $\mathrm{UTD}-0$ & No -0 & $\mathrm{UTD}-0$ & No -0 & No -0 & $\mathrm{UTD}-0$ & $\mathrm{UTD}-0$ & $\mathrm{UTD}-0$ & $\mathrm{UTD}-0$ \\
\hline \multicolumn{13}{|l|}{ INTERNAL VALIDITY - BIAS AND CONFOUNDING } \\
\hline Q14 - Study participants blinded to treatment & Yes -1 & Yes -1 & Yes -1 & Yes -1 & Yes -1 & Yes -1 & Yes -1 & Yes -1 & $\mathrm{UTD}-0$ & Yes -1 & Yes -1 & Yes -1 \\
\hline Q15 - Blinded outcome assessment & UTD - 0 & Yes -1 & Yes -1 & Yes -1 & -1 & -1 & -1 & -1 & UTl & 1 & -1 & Yes -1 \\
\hline Q16 - Any da & Yes -1 & Yes -1 & Yes -1 & Yes -1 & -1 & Yes -1 & -1 & Yes -1 & Yes -1 & $\mathrm{Ye}$ & Yes -1 & Yes -1 \\
\hline Q17 - Analyses adjust for differing lengths of follow-up & UTD - 0 & Yes -1 & Yes -1 & Yes -1 & Yes -1 & Yes -1 & Yes -1 & Yes -1 & Yes -1 & Yes -1 & Yes -1 & Yes -1 \\
\hline Q18 - Appropriate statistical tests performed & Yes -1 & Yes -1 & Yes -1 & Yes -1 & Yes -1 & Yes -1 & Yes -1 & Yes -1 & Yes -1 & Yes -1 & Yes -1 & Yes -1 \\
\hline Q19 - Compliance with interventions was reliable & Yes -1 & Yes -1 & Yes -1 & Yes -1 & Yes -1 & Yes -1 & & Yes -1 & Yes -1 & & Yes -1 & Yes -1 \\
\hline Q20 - Outcome measures were reliable and valid & & Yes -1 & Yes -1 & Yes -1 & & Yes -1 & & & Yes -1 & Yes -1 & Yes -1 & Yes -1 \\
\hline $\begin{array}{l}\text { Q21 - All participants recruited from the same source } \\
\text { population }\end{array}$ & Yes -1 & UTD -0 & $\mathrm{UTD}-0$ & $\mathrm{UTD}-0$ & Yes -1 & No -0 & Yes -1 & Yes -1 & $\mathrm{UTD}-0$ & UTD -0 & No -0 & UTD -0 \\
\hline Q22 - All participants recruited over the same time period & $\mathrm{UTD}-0$ & $\mathrm{UTD}-0$ & $\mathrm{UTD}-0$ & $\mathrm{UTD}-0$ & No -0 & -0 & $\mathrm{UTD}-0$ & UTD - 0 & UTD - 0 & -0 & UTD - 0 & $\mathrm{UTD}-0$ \\
\hline Q23 - Participants randomized to treatment(s) & Yes -1 & Yes -1 & Yes -1 & No -0 & Yes -1 & Yes - 1 & No -0 & Yes - 1 & No -0 & Yes -1 & Yes - 1 & Yes -1 \\
\hline $\begin{array}{l}\text { Q24 - Allocation of treatment concealed from } \\
\text { investigators and participants }\end{array}$ & $\mathrm{UTD}-0$ & Yes -1 & Yes -1 & $\mathrm{UTD}-0$ & Yes -1 & Yes - 1 & UTD - 0 & Yes - 1 & UTD - 0 & Yes -1 & Yes - 1 & Yes -1 \\
\hline Q25 - Adequ & & & & & & & No -0 & & & & & No -0 \\
\hline $\begin{array}{l}\text { Q26 - Losses to follow-up taken into account } \\
\text { POWER }\end{array}$ & Yes -1 & Yes -1 & Yes -1 & Yes -1 & Yes -1 & Yes - 1 & UTD - 0 & Yes -1 & Yes -1 & Yes -1 & Yes - 1 & Yes -1 \\
\hline $\begin{array}{l}\text { Q27 - Power analysis to detect treatment effect at } \\
\text { significance level of } 0.05\end{array}$ & No -0 & Yes -1 & Yes -1 & No -0 & No -0 & Yes - 1 & No -0 & No -0 & No -0 & Yes -1 & No -0 & Yes -1 \\
\hline TOTAL & 17 & 21 & 22 & 17 & 23 & 20 & 17 & 22 & 14 & 22 & 20 & 21 \\
\hline
\end{tabular}

*UDT - Unable to determine. 
As in most of the articles included, the therapeutic targets of tDCS were the motor and prefrontal cortex. The study by Benninger et al. (2010) used a traditional battery-operated device and a target area was stimulated each day, alternating the anode position between sessions (starting with the motor area). In this way, each location had been stimulated four times. It was not possible to find information regarding the method of targeting the areas, but the authors report that the electrode was positioned $10 \mathrm{~mm}$ anterior to $\mathrm{Cz}$ (motor and pre-motor cortex). The study by Dagan et al. (2018) applied tDCS through a system composed of 6 small Ag / AgCl stimulation electrodes, and both targets were stimulated simultaneously, in two sessions for each group. The authors report that they used the international 10-20 electroencephalogram system to locate the areas.

The main cognitive and non-motor measures included visuomotor speed and procedural learning, depressive symptoms and executive functions. Motor measurements included gait, bradykinesia, functional mobility, aspects related to freezing of gait, global clinical condition. The results showed that multisite tDCS was superior only to gait and bradykinesia measures in the study by Benninger et al. (2010), while in the study by Dagan et al. (2018) was effective for all outcome measures.

\subsection{Trials using multisite rTMS plus tDCS in Parkinson's disease}

One of the selected studies used high frequency rTMS and tDCS, simultaneously (Chang et al., 2017) (see Table 4). The study compared two treatment conditions: rTMS plus tDCS, and real rTMS plus sham tDCS. The diagnoses were made by neurologists with experience in movement disorders and were based on medical history, physical examination and neuroimaging studies. The Modified Hoehn and Yahr Scale was used as a clinical evaluation to characterize the participants, most of which were concentrated between stages 2 and 3 .

Whilst rTMS was applied over M1 corresponding to the lower limbs, tDCS was applied over DLPFC. The international 10-20 electroencephalogram system was used to identify F3, while the ideal stimulation point for M1 was defined using the MEP hotspot. After each session of the NIBS, adverse effects were evaluated, which include anxiety, fear, headache, tinnitus, dizziness, hearing loss, fainting, nausea and vomiting. A series of motor and cognitive measures were collected, however, for most of them, there was no difference between groups after treatment. Only in the executive function outcome there was a greater increase in dual-mode intervention.

\subsection{Quality assessment}

Most of the included studies were classified with good quality (Benninger et al., 2010; Benninger et al., 2011; Brys et al., 2016; Chang et al., 2017; Cohen et al., 2018; Dagan et al., 2018; Fricke et al., 2019; Oh et al., 2015), and the others were of moderate (Aftanas et al., 2018; Khedr et al., 2006; Lomarev et al., 2006; or low quality (Spagnolo et al., 2014) (Table 5). In general, the studies analyzed clearly described the main clinical characteristics of the participants, the intervention methods, the main outcome measures, as well as randomization and blinding procedures. However, none of the studies provided sufficient information regarding external validity, limiting the generalization of the representativeness of the results of the studies in the population from which the participants were derived. In addition, only 5 studies mention perform a power analysis to determine the sample size needed to detect a significant difference in effect size for one or more outcome measures.

\section{Discussion}

This review showed an increasing interest in the application of the multisite NIBS in PD, with articles published between the years 2005 to 2019. In addition, there are a total of 387 patients, usually between the mild and moderate stages of the disease. Although tDCS is a therapy that is easy to apply when compared to other modalities, most studies presented here used TMS as therapy. Despite the results being encouraging for the use of the multisite NIBS, most of the trials showed that this modality was only more effective for the motor component, or for the cognitive and / or non-motor, separately.

Therefore, the indication of multisite NIBS approach in PD management should be carried out with caution and deserves scientific deepening. In the future, clinical trials considering methodological issues, such as the cortical network interplay, precision and reproducibility in multisite montage, and inter and intra-individual variability in response to treatment are useful to clarify the clinical significance of the findings. In this section, we present a critical view of main findings, discuss the state-of-the-art, lack of evidence and propose future directions. 


\subsection{Patient characteristics}

A large majority of the studies presented describe the most relevant characteristics for the characterization of participants in the baseline, however, they do not address how they could interfere in the interpretation of the results. A long-term follow-up study (Málly et al., 2018) of the use of NIBS (rTMS and tDCS), showed that the therapy is able to slow the progression of the disease, but that age is the main predictor of its effect. In other clinical populations such as stroke, these predictors of response may be related to the severity of symptoms, the size and location of the lesions, the etiology of the stroke and the time from symptom onset to intervention (OvadiaCaro et al., 2019). Similarly, studies using NIBS in PD show evidence for the need to consider clinical and demographic aspects more carefully, as well as observe how these characteristics could interfere with therapy (Kishore et al., 2012; Udupa \& Chen, 2013).

Several factors involving drug therapy and the application of NIBS must also be taken into account. Most of the studies reviewed here report the application of the intervention associated with the medication, as well as the levodopa equivalent dose (LED) and the medication conditions (on or off stage). However, only two studies included the assessment of outcomes in both conditions. Studies show that the plastic effects produced by NIBS techniques are highly dependent on the dopamine concentration (Dileone et al., 2017; Monte-Silva et al., 2009; Nitsche et al., 2009; Nitsche et al., 2010), thus highlighting the importance of a specific and adequate dosage of dopamine during therapy (Monte-Silva et al., 2010; Thirugnanasambandam et al., 2011). In addition, it is believed that the interaction of the medication with the NIBS may confuse the results, because of a possible ceiling effect (Fregni et al., 2005). Therefore, including an assessment in the "off" state of the medication can provide a more sensitive measure of the real benefits of the therapy.

The lack of objective biomarkers, the diversity of symptoms and the heterogeneity of disease progression, can hinder and interfere with the results of clinical trials. The main motor symptoms such as bradykinesia, rest tremor and rigidity are the most used and important clinical markers for the diagnosis of PD, however, they usually only appear when a relatively advanced neurodegenerative stage is present (Fearnley \& Lees, 1991). Thus, other biomarkers such as brain-derived neurotrophic factor (BDNF), and neuroimaging techniques such as magnetic resonance imaging can be useful to facilitate early diagnosis, detect disease progression and improve treatments in PD (Costa et al., 2015; Delenclos et al., 2016; Miller \& O'Callaghan, 2015). However, even if several biomarkers for PD have been developed so far (He et al., 2018), they do not have good specificity and sensitivity when applied individually, and are not yet commonly inserted as previous measures in clinical trials.

Baseline clinical characteristics, such as disease stage, time of diagnosis, clinical type, levodopa equivalent dose, can be considered as moderating variables for the effect of NIBS. In the future, we recommend an approach that takes into account possible response biomarkers associated with a careful consideration of such characteristics prior to treatment. Thus, the choice of cortical targets and montages can be optimized and directed towards more effective management, in addition to promoting a better understanding about the influence of these aspects in the treatment.

\subsection{Beyond the cortical target: Cortical network interplay}

With the possibility of modulating specific brain regions or networks, NIBS has become a potential for the treatment of various symptoms related to PD. In the studies reviewed, there was no great variation regarding the choice of therapeutic targets, and the choice was based on the symptoms of the disease. In addition to symptoms, neuroimaging studies suggest an intra and interhemispheric imbalance in Parkinson's disease. Previous studies indicate a decrease in the functional connectivity of frontal, occipital and parietal brain areas, as well as an increase within the sensory-motor networks (compensatory reorganization) (Baggio et al., 2015; de Schipper et al., 2018; Göttlich et al., 2013; Tessitore et al., 2019). Cortical network impairment appears to precede and be correlated with some symptoms, such as memory and recognition deficits (Ibarretxe-Bilbao et al., 2011), depression (Liao et al., 2020), motor decline (Manza et al., 2016), in addition to being critical to differentiate patients with and without cognitive impairment (Wolters et al., 2019). Thinking about cortical networks in PD is of great value in guiding the choice of therapeutic targets and going beyond the existing symptoms.

NIBS appears to have the potential to promote direct effects on the underlying cortex, as well as on distant networks (Polania et al., 2018). Thus, the 
main focus of treatment should not be just the stimulation of motor and / or frontal regions, but through them, reach these deeper cortical networks, in order to promote multimodal connections and restore balance. However, for networks to become the target of neuromodulatory interventions, it must be kept in mind that the connections are highly specific for each patient, in addition to requiring greater knowledge about the effect of stimulation on them (Ruffini et al., 2018).

Unfortunately, most of the reviewed studies evaluate the response of therapy only using clinical pencil-paper scales, which reflect only aspects related to the symptoms of the disease. Therefore, the insertion of outcome measures that address neurophysiological aspects, for example, neuroimaging or electroencephalography, can improve the selection of targets and monitor the NIBS response more effectively. An alternative would be the application of protocols with the simultaneous combination of NIBS with electroencephalography (Thut et al., 2017), functional near-infrared spectroscopy (fNIRS) (Curtin et al., 2019), magnetic resonance (Jung et al., 2020) or multimodal applications (Peters et al., 2020). Therefore, further studies may then be needed to determine whether the altered clinical outcome is directly related to the dynamics of cortical networks in a linear or non-linear direction.

\subsection{Rethinking location system}

Non-invasive methods to locate therapeutic targets, including neuroimaging, transcranial magnetic stimulation and electroencephalogram, are already described in the literature (Dmochowski et al., 2017; Pommier et al., 2017; Wang et al., 2020). Among the studies reviewed, two approaches that guide the location of the target were reported in most of them. The first includes specific head measurements using the international 10/20 EEGcoordinate system (Benninger et al., 2010; Chang et al., 2017; Dagan et al., 2018;), while the second concerns the use of TMS to locate the hotspot (Benninger et al., 2011; Brys et al., 2016; Chang et al., 2017; Cohen et al., 2018; Khedr et al., 2006; Lomarev et al., 2006; Spagnolo et al., 2014). Only three studies included magnetic resonance imaging (MRI) guided neuronavigation as a method (Aftanas et al., 2018; Fricke et al., 2019; Oh et al., 2015).

Based on the anatomical relationship of skull dimensions and brain anatomy (Klem, 1999), the 10/20 EEG coordinate system is widely used in clinical research, however, it is a generalized measure and does not cover individual differences. In a study with hemiparetic and healthy children, the comparison between the location of M1 using the 10/20 EEG coordinates and the TMS hotspot showed differences in distance between the points. In addition, the TMS hotspot for most children was outside the perimeter of the tDCS electrode (Rich et al., 2017). Similarly, another study to compare the location of the left DLPFC through 10-20 EEG system with neuronavigation guided by MRI in healthy subjects, suggests different distributions of electric fields between the methods and the neuronavigation finds the DLPFC more latero-posteriorly (De Witte et al., 2018). Besides that, performing an analysis of the anatomical locations of the individual motor hotspot, a study revealed that in most participants it was not located on the anatomical limits M1, which can contribute to the variability of the results (Lefebvre et al., 2019).

The neuronavigation guided by magnetic resonance is a more individualized localization method that uses the patient's MRI data to determine the point of the scalp closest to the cortical location target (Peleman et al., 2010; Sparing et al., 2010). For TMS, this method can provide better feedback for real-time adjustment of the position and orientation of the coil during therapy (Richter et al., 2013; Rusjan et al., 2010). In investigations involving tDCS, taking the location method into consideration may be relevant due to the fact that the electrical fields are influenced by the assembly used (Bai et al., 2014; Opitz et al., 2018). Thus, using a neuronavigation system can be more assertive to locate therapeutic targets individually.

\subsection{Individualized optimal approach}

The studies reviewed here consider only the location of the cortical target, without adhering to the orientation of the current flow. There is a consensus on the fact that the ideal configuration of the tDCS electrode and the TMS coil can induce changes in the electric field (Janssen et al., 2015; Laakso et al., 2016). Traditional TMS coils cause focal stimulation in the cortex underlying their center, however, multiple coil arrays can be an alternative to activate deeper regions of the brain and optimize the stimulation of different targets without the need to move the coil during application (Koponen et al., 2018; Wei et al., 2017). The conventional tDCS setting induces an unpredictable diffuse current flow in generalized brain areas, that is, the higher current density may not be directly under the target region below the 
electrodes (Datta et al., 2009; Faria et al., 2011). In this sense, HD-tDCS can be an alternative, because it uses a series of small electrodes that promote a current flow restricted to the area under the electrodes, which increases the accuracy and the focus of the current on the targets (Seo et al., 2017).

Technological advances, together with the development of biomarkers associated with the NIBS response, can help to individualize therapy and promote more controlled stimulation protocols (Terranova et al., 2019). The variable response occurs due to multiple intra and interindividual factors such as age, sex, time of day, influences on lifestyle, genetics, differences in electrical fields (Guerra et al., 2020; Huang et al., 2017; Laakso et al., 2019), in addition to medication status, which seems to be a key factor for the level of effectiveness in people with PD (Brittain and Cagnan, 2018). Preliminary evidence suggests that details of the anatomy of the brain, brain-scalp distance and the thickness of the cerebrospinal fluid, can lead to differences in the effects of TMS and tDCS, and that these characteristics are extremely important for the calculation of the ideal stimulation configuration (Dmochowski et al., 2011; Lee et al., 2018; Syeda et al., 2017). The reduction of inter-individual variability may be possible when conducting current flow modeling.

Taking these aspects into consideration, computational models of current flow in brain stimulation have been recently investigated, providing a greater understanding of how the current behaves (Saturnino et al., 2019). So far, computational models seem to be the safest and most individualized measure to accurately determine the electric field at each therapeutic dosage (Salvador et al., 2019). A recent study using flow modeling, points out that controlling the stimulatory dose individually can eliminate the variation in the intensity of the electric field in the cortical targets between individuals (Evans et al., 2020). Despite the efforts and advances, such as the possibility of realtime modeling (Stenroos \& Koponen, 2019), and the growing interest in implementing modeling in studies with NIBS, access to this tool by clinicians and professionals still seems to remain limited. Future studies can elicit the individual effects of NIBS, by incorporating the electric field modeling previously.

\section{Conclusions}

In conclusion, there is insufficient evidence to determine if the multisite NIBS is an effective therapeutic modality to simultaneously improve the motor and cognitive aspects of Parkinson's disease. Although most studies select and associate motor and prefrontal cortical targets, the parameters of TMS and tDCS stimulation (coil shape, electrode size, intensity, frequency, duration and number of sessions) varied considerably between protocols. Future trials should consider clinical aspects related to the disease with greater methodological rigor, perform a more precise location of cortical targets, as well as address the interaction between neural networks. These aspects will be useful to clarify the clinical significance of the findings and to systematize the application of the multisite NIBS.

\section{Conflict of interest}

The authors declared no potential conflicts of interest.

\section{References}

Aftanas, L. I., Gevorgyan, M. M., Zhanaeva, S. Y., Dzemidovich, S. S., Kulikova, K. I., Danilenko, K. V., \& Idova, G. V. (2018). Therapeutic effects of repetitive transcranial magnetic stimulation (rTMS) on neuroinflammation and neuroplasticity in patients with Parkinson's disease: a placebo-controlled study. Bulletin of Experimental Biology and Medicine, 165(2), 195-199.

Alagapan, S., Riddle, J., Huang, W. A., Hadar, E., Shin, H. W., \& Fröhlich, F. (2019). Network-targeted, multi-site direct cortical stimulation enhances working memory by modulating phase lag of low-frequency oscillations. Cell Reports, 29(9), 25902598.

Arksey, H., \& O’Malley, L. (2005). Scoping studies: towards a methodological framework. International Journal of Social Research Methodology, 8(1), 19-32.

Bai, S., Dokos, S., Ho, K. A., \& Loo, C. (2014). A computational modelling study of transcranial direct current stimulation montages used in depression. Neuroimage, 87, 332-344.

Baggio, H. C., Segura, B., \& Junque, C. (2015). Resting-state functional brain networks in Parkinson's Disease. CNS Neuroscience \& Therapeutics, 21(10), 793-801.

Benninger, D. H., Lomarev, M., Lopez, G., Wassermann, E. M., Li, X., Considine, E., \& Hallett, M. (2010). Transcranial direct current stimulation for the treatment of Parkinson's Disease. Journal of Neurology, Neurosurgery and Psychiatry, 81(10), 1105-1111.

Benninger, D. H., Berman, B. D., Houdayer, E., Pal, N., Luckenbaugh, D. A., Schneider, L., Miranda, S., \& Hallett, M. (2011). Intermittent theta-burst transcranial magnetic stimulation for treatment of Parkinson Disease. Neurology, 76(7), 601-609.

Benninger, D. H., \& Hallett, M. (2015). Non-invasive brain stimulation for Parkinson's Disease: current concepts and outlook 2015. NeuroRehabilitation, 37(1), 1124. Doi: 10.3233/NRE151237 
Brittain, J. S., \& Cagnan, H. (2018). Recent trends in the use of electrical neuromodulation in Parkinson's disease. Current Behavioral Neuroscience Reports, 5(2), 170-178.

Broeder, S., Nackaerts, E., Heremans, E., Vervoort, G., Meesen, R., Verheyden, G., \& Nieuwboer, A. (2015). Transcranial direct current stimulation in Parkinson's disease: Neurophysiological mechanisms and behavioral effects. Neuroscience \& Biobehavioral Reviews, 57, 105-117.

Brown, M. J., Goldenkoff, E. R., Chen, R., Gunraj, C., \& Vesia, M. (2019). Using dual-site transcranial magnetic stimulation to probe connectivity between the dorsolateral prefrontal cortex and ipsilateral primary motor cortex in humans. Brain Sciences, 9(8), 177.

Brys, M., Fox, M. D., Agarwal, S., Biagioni, M., Dacpano, G., Kumar, P., Pirraglia, E., Chen, R., Wu, A., Fernandez, H., Wagle Shukla, A., Lou, J. S., Gray, Z., Simon, D. K., Di Rocco, A., \& Pascual-Leone, A. (2016). Multifocal repetitive TMS for motor and mood symptoms of Parkinson disease: A randomized trial. Neurology, 87(18), 1907-1915.

Chang, W. H., Kim, M. S., Park, E., Cho, J. W., Youn, J., Kim, Y. K., \& Kim, Y. H. (2017). Effect of dual-mode and dual-site noninvasive brain stimulation on freezing of gait in patients with Parkinson disease. Archives of Physical Medicine and Rehabilitation, 98(7), 1283-1290.

Chen, K. H. S., \& Chen, R. (2019). Invasive and noninvasive brain stimulation in Parkinson's disease: clinical effects and future perspectives. Clinical Pharmacology \& Therapeutics, 106(4), 763-775.

Chou, Y. H., Hickey, P. T., Sundman, M., Song, A. W., \& Chen, N. K. (2015). Effects of repetitive transcranial magnetic stimulation on motor symptoms in Parkinson disease: a systematic review and meta-analysis. JAMA Neurology, 72(4), 432-440.

Cohen, O. S., Rigbi, A., Yahalom, G., Warman-Alaluf, N., Nitsan, Z., Zangen, A., \& Hassin-Baer, S. (2018). Repetitive Deep TMS for Parkinson Disease: A 3-Month Double-Blind, Randomized Sham-Controlled Study. Journal of Clinical Neurophysiology: official publication of the American Electroencephalographic Society, 35(2), 159-165.

Costa, A., Peppe, A., Carlesimo, G. A., Zabberoni, S., Scalici, F., Caltagirone, C., \& Angelucci, F. (2015). Brain-derived neurotrophic factor serum levels correlate with cognitive performance in Parkinson's disease patients with mild cognitive impairment. Frontiers in Behavioral Neuroscience, 9, 253.

Curtin, A., Tong, S., Sun, J., Wang, J., Onaral, B., \& Ayaz, H. (2019). A systematic review of integrated functional near-infrared spectroscopy (fNIRS) and transcranial magnetic stimulation (TMS) studies. Frontiers in Neuroscience, 13, 84.

Dagan, M., Herman, T., Harrison, R., Zhou, J., Giladi, N., Ruffini, G., Manor, B., \& Hausdorff, J. M. (2018). Multitarget transcranial direct current stimulation for freezing of gait in Parkinson's disease. Movement Disorders: Official Journal of the Movement Disorder Society, 33(4), 642-646.

Datta, A., Bansal, V., Diaz, J., Patel, J., Reato, D., \& Bikson, M. (2009). Gyri-precise head model of transcranial direct current stimulation: improved spatial focality using a ring electrode versus conventional rectangular pad. Brain Stimulation, 2(4), 201-207.e1.

Delenclos, M., Jones, D. R., McLean, P. J., \& Uitti, R. J. (2016). Biomarkers in Parkinson's disease: Advances and strategies. Parkinsonism \& Related Disorders, 22, Suppl 1, S106-S110.

Deng, Z. D., Lisanby, S. H., \& Peterchev, A. V. (2013). Electric field depth-focality tradeoff in transcranial magnetic stimulation: simulation comparison of 50 coil designs. Brain Stimulation, 6(1), 1-13

de Schipper, L. J., Hafkemeijer, A., van der Grond, J., Marinus, J., Henselmans, J. M., \& van Hilten, J. J. (2018). Altered whole-brain and network-based functional connectivity in Parkinson's disease. Frontiers in Neurology, 9, 419. Doi: 10.3389/fneur.2018.00419

De Witte, S., Klooster, D., Dedoncker, J., Duprat, R., Remue, J., \& Baeken, C. (2018). Left prefrontal neuronavigated electrode localization in tDCS: 10-20 EEG system versus MRI-guided neuronavigation. Psychiatry Research. Neuroimaging, 274, $1-6$.

Dileone, M., Carrasco-López, M. C., Segundo-Rodriguez, J. C., Mordillo-Mateos, L., López-Ariztegui, N., Alonso-Frech, F., Catalan-Alonso, M. J., Obeso, J. A., Oliviero, A., \& Foffani, G. (2017). Dopamine-dependent changes of cortical excitability induced by transcranial static magnetic field stimulation in Parkinson's disease. Scientific Reports, 7(1), 4329.

Dmochowski, J. P., Datta, A., Bikson, M., Su, Y., \& Parra, L. C. (2011). Optimized multi-electrode stimulation increases focality and intensity at target. Journal of Neural Engineering, 8(4), 046011.

Dmochowski, J. P., Koessler, L., Norcia, A. M., Bikson, M., \& Parra, L. C. (2017). Optimal use of EEG recordings to target active brain areas with transcranial electrical stimulation. Neuroimage, 157, 69-80.

Downs, S. H., \& Black, N. (1998). The feasibility of creating a checklist for the assessment of the methodological quality both of randomised and non-randomised studies of health care interventions. Journal of Epidemiology \& Community Health, 52(6), 377-384.

Elsner, B., Kugler, J., Pohl, M., \& Mehrholz, J. (2016). Transcranial direct current stimulation (tDCS) for idiopathic Parkinson's disease. Cochrane Database of Systematic Reviews, 7(7), CD010916.

Esser, S. K., Huber, R., Massimini, M., Peterson, M. J., Ferrarelli, F., \& Tononi, G. (2006). A direct demonstration of cortical LTP in humans: a combined TMS/EEG study. Brain Research Bulletin, 69(1), 86-94.

Evans, C., Bachmann, C., Lee, J. S., Gregoriou, E., Ward, N., \& Bestmann, S. (2020). Dose-controlled tDCS reduces electric field intensity variability at a cortical target site. Brain Stimulation, 13(1), 125-136.

Faria, P., Hallett, M., \& Miranda, P. C. (2011). A finite element analysis of the effect of electrode area and inter-electrode distance on the spatial distribution of the current density in tDCS. Journal of Neural Engineering, 8(6), 066017.

Fearnley, J. M., \& Lees, A. J. (1991). Ageing and Parkinson's disease: substantia nigra regional selectivity. Brain, 114(5), 2283-2301.

Fischer, D. B., Fried, P. J., Ruffini, G., Ripolles, O., Salvador, R., Banus, J., Ketchabaw, W. T., Santarnecchi, E., Pascual-Leone, A., \& Fox, M. D. (2017). Multifocal tDCS targeting the resting state motor network increases cortical excitability beyond traditional tDCS targeting unilateral motor cortex. Neuroimage, 157, 34-44

Fregni, F., Simon, D. K., Wu, A., \& Pascual-Leone, A. (2005). Non-invasive brain stimulation for Parkinson's disease: a systematic review and meta-analysis of the literature. Journal of Neurology, Neurosurgery and Psychiatry, 76(12), 1614-1623.

Fregni, F., \& Pascual-Leone, A. (2007). Technology insight: noninvasive brain stimulation in neurology-perspectives on the 
therapeutic potential of rTMS and tDCS. Nature clinical practice. Neurology, 3(7), 383-393.

Fricke, C., Duesmann, C., Woost, T. B., von Hofen-Hohloch, J., Rumpf, J. J., Weise, D., \& Classen, J. (2019). Dual-site transcranial magnetic stimulation for the treatment of parkinson's Disease. Frontiers in Neurology, 10, 174.

GBD 2016 Parkinson's Disease Collaborators (2018). Global, regional, and national burden of Parkinson's disease, 19902016: a systematic analysis for the Global Burden of Disease Study 2016. The Lancet. Neurology, 17(11), 939-953.

Goldman, J. G., Vernaleo, B. A., Camicioli, R., Dahodwala, N., Dobkin, R. D., Ellis, T., Galvin, J. E., Marras, C., Edwards, J., Fields, J., Golden, R., Karlawish, J., Levin, B., Shulman, L., Smith, G., Tangney, C., Thomas, C. A., Tröster, A. I., Uc, E. Y., Coyan, N., ... Simmonds, D. (2018). Cognitive impairment in Parkinson's disease: a report from a multidisciplinary symposium on unmet needs and future directions to maintain cognitive health. NPJ Parkinson's Disease, 4(1), 19.

Goodwill, A. M., Lum, J. A., Hendy, A. M., Muthalib, M., Johnson, L., Albein-Urios, N., \& Teo, W. P. (2017). Using non-invasive transcranial stimulation to improve motor and cognitive function in Parkinson's disease: a systematic review and meta-analysis. Scientific Reports, 7(1), 14840.

Göttlich, M., Münte, T. F., Heldmann, M., Kasten, M., Hagenah, J., \& Krämer, U. M. (2013). Altered resting state brain networks in Parkinson's disease. PloS One, 8(10), e77336.

Guerra, A., López-Alonso, V., Cheeran, B., \& Suppa, A. (2020). Variability in non-invasive brain stimulation studies: reasons and results. Neuroscience Letters, 719, 133330.

Guleyupoglu, B., Schestatsky, P., Edwards, D., Fregni, F., \& Bikson, M. (2013). Classification of methods in transcranial electrical stimulation (tES) and evolving strategy from historical approaches to contemporary innovations. Journal of Neuroscience Methods, 219(2), 297-311.

Hallett, M. (2007). Transcranial magnetic stimulation: a primer. Neuron, 55(2), 187-199.

He, R., Yan, X., Guo, J., Xu, Q., Tang, B., \& Sun, Q. (2018). Recent advances in biomarkers for Parkinson's disease. Frontiers in Aging Neuroscience, 10, 305.

Hess, C. W. (2013). Modulation of cortical-subcortical networks in Parkinson's disease by applied field effects. Frontiers in Human Neuroscience, 7, 565.

Hooper, P., Jutai, J. W., Strong, G., \& Russell-Minda, E. (2008). Age-related macular degeneration and low-vision rehabilitation: a systematic review. Canadian Journal of Ophthalmology, 43(2), 180-187.

Huang, Y. Z., Lu, M. K., Antal, A., Classen, J., Nitsche, M., Ziemann, U., Ridding, M., Hamada, M., Ugawa, Y., Jaberzadeh, S., Suppa, A., Paulus, W., \& Rothwell, J. (2017). Plasticity induced by non-invasive transcranial brain stimulation: a position paper. Clinical Neurophysiology: Official Journal of the International Federation of Clinical Neurophysiology, 128(11), 2318-2329.

Ibarretxe-Bilbao, N., Zarei, M., Junque, C., Marti, M. J., Segura, B., Vendrell, P., Valldeoriola, F., Bargallo, N., \& Tolosa, E. (2011). Dysfunctions of cerebral networks precede recognition memory deficits in early Parkinson's disease. NeuroImage, 57(2), 589-597.

Janssen, A. M., Oostendorp, T. F., \& Stegeman, D. F. (2015). The coil orientation dependency of the electric field induced by TMS for M1 and other brain areas. Journal of Neuroengineering and Rehabilitation, 12(1), 47.
Jung, J., Bungert, A., Bowtell, R., \& Jackson, S. R. (2020). Modulating brain networks with transcranial magnetic stimulation over the primary motor cortex: a concurrent TMS/fMRI study. Frontiers in Human Neuroscience, 14, 31.

Kalia, L. V., \& Lang, A. E. (2015). Parkinson's disease. The Lancet, 386(9996), 896-912.

Khedr, E. M., Rothwell, J. C., Shawky, O. A., Ahmed, M. A., \& Hamdy, A. (2006). Effect of daily repetitive transcranial magnetic stimulation on motor performance in Parkinson's disease. Movement Disorders: Official Journal of the Movement Disorder Society, 21(12), 2201-2205.

Kishore, A., Popa, T., Velayudhan, B., Joseph, T., Balachandran, A., \& Meunier, S. (2012). Acute dopamine boost has a negative effect on plasticity of the primary motor cortex in advanced Parkinson's disease. Brain, 135(7), 2074-2088.

Klem, G. H. (1999). The ten-twenty electrode system of the international federation. the international federation of clinical neurophysiology. Electroencephalography and Clinical Neurophysiology. Suppl., 52, 3-6.

Koponen, L. M., Nieminen, J. O., \& Ilmoniemi, R. J. (2018). Multi-locus transcranial magnetic stimulation-theory and implementation. Brain Stimulation, 11(4), 849-855.

Laakso, I., Tanaka, S., Mikkonen, M., Koyama, S., Sadato, N., \& Hirata, A. (2016). Electric fields of motor and frontal tDCS in a standard brain space: a computer simulation study. Neuroimage, 137, 140-151.

Laakso, I., Mikkonen, M., Koyama, S., Hirata, A., \& Tanaka, S. (2019). Can electric fields explain inter-individual variability in transcranial direct current stimulation of the motor cortex? Scientific Reports, 9(1), 626.

Lang, A. E., \& Obeso, J. A. (2004). Challenges in Parkinson's disease: restoration of the nigrostriatal dopamine system is not enough. The Lancet Neurology, 3(5), 309-316.

Lee, E. G., Rastogi, P., Hadimani, R. L., Jiles, D. C., \& Camprodon, J. A. (2018). Impact of non-brain anatomy and coil orientation on inter-and intra-subject variability in TMS at midline. Clinical Neurophysiology: Official Journal of the International Federation of Clinical Neurophysiology, 129(9), 18731883.

Lefebvre, S., Jann, K., Schmiesing, A., Ito, K., Jog, M., Schweighofer, N., Wang, D., \& Liew, S. L. (2019). Differences in high-definition transcranial direct current stimulation over the motor hotspot versus the premotor cortex on motor network excitability. Scientific Reports, 9(1), 17605.

Levac, D., Colquhoun, H., \& O'Brien, K. K. (2010). Scoping studies: advancing the methodology. Implementation Science, $5(1), 69$.

Liao, H., Fan, J., Shen, Q., Cai, S., Wang, M., Wang, C., Zhang, H., Liu, J., Zhu, X., \& Tan, C. (2020). Alterations of interhemispheric functional connectivity in parkinson's disease with depression: a resting-state functional MRI study. Frontiers in Human Neuroscience, 14, 193.

Litvan, I., Aarsland, D., Adler, C. H., Goldman, J. G., Kulisevsky, J., Mollenhauer, B.,... \& Weintraub, D. (2011). MDS Task Force on mild cognitive impairment in Parkinson's disease: critical review of PD-MCI. Movement Disorders, 26(10), 18141824.

Lomarev, M. P., Kanchana, S., Bara-Jimenez, W., Iyer, M., Wassermann, E. M., \& Hallett, M. (2006). Placebo-controlled study of rTMS for the treatment of Parkinson's disease. Movement Disorders: Official Journal of the Movement Disorder Society, 21(3), 325-331. 
Málly, J., Stone, T. W., Sinkó, G., Geisz, N., \& Dinya, E. (2018). Long term follow-up study of non-invasive brain stimulation (NBS) (rTMS and tDCS) in Parkinson's disease (PD). Strong age-dependency in the effect of NBS. Brain Research Bulletin, $142,78-87$

Manza, P., Zhang, S., Li, C. S. R., \& Leung, H. C. (2016). Restingstate functional connectivity of the striatum in early-stage $\mathrm{P}$ arkinson's disease: Cognitive decline and motor symptomatology. Human Brain Mapping, 37(2), 648-662.

Medeiros, L. F., de Souza, I. C., Vidor, L. P., de Souza, A., Deitos, A., Volz, M. S., Fregni, F., Caumo, W., \& Torres, I. L. (2012). Neurobiological effects of transcranial direct current stimulation: a review. Frontiers in Psychiatry, 3, 110.

Miller, D. B., \& O'Callaghan, J. P. (2015). Biomarkers of Parkinson's disease: present and future. Metabolism, 64(3), S40-S46.

Moher, D., Shamseer, L., Clarke, M., Ghersi, D., Liberati, A., Petticrew, M., Shekelle, P., Stewart, L. A., \& PRISMA-P Group (2015). Preferred reporting items for systematic review and meta-analysis protocols (PRISMA-P) 2015 statement.

Monte-Silva, K., Kuo, M. F., Thirugnanasambandam, N., Liebetanz, D., Paulus, W., \& Nitsche, M. A. (2009). Dose-dependent inverted U-shaped effect of dopamine (D2-like) receptor activation on focal and nonfocal plasticity in humans. Journal of Neuroscience, 29(19), 6124-6131.

Monte-Silva, K., Liebetanz, D., Grundey, J., Paulus, W., \& Nitsche, M. A. (2010). Dosage-dependent non-linear effect of L-dopa on human motor cortex plasticity. The Journal of Physiology, 588(18), 3415-3424.

Monte-Silva, K., Kuo, M. F., Hessenthaler, S., Fresnoza, S., Liebetanz, D., Paulus, W., \& Nitsche, M. A. (2013). Induction of late LTP-like plasticity in the human motor cortex by repeated noninvasive brain stimulation. Brain Stimulation, 6(3), 424-432.

Nieoullon, A., \& Goff, L. K. L. (1992). Cellular interactions in the striatum involving neuronal systems using "classical" neurotransmitters: possible functional implications. Movement Disorders: Official Journal of the Movement Disorder Society, 7(4), 311-325.

Nitsche, M. A., Kuo, M. F., Grosch, J., Bergner, C., Monte-Silva, K., \& Paulus, W. (2009). D1-receptor impact on neuroplasticity in humans. Journal of Neuroscience, 29(8), 2648-2653.

Nitsche, M. A., Monte-Silva, K., Kuo, M. F., \& Paulus, W. (2010). Dopaminergic impact on cortical excitability in humans. Reviews in the Neurosciences, 21(4), 289-298.

Oh, E., Park, S., Lim, J., Lee, A. Y., Bok, S. K., \& Song, H. J. (2015). High Frequency Repetitive Transcranial Magnetic Stimulation for Freezing of Gait and Nonmotor Symptoms in Parkinson's Disease. Journal of the Korean Neurological Association, 33(4), 297-305.

Opitz, A., Yeagle, E., Thielscher, A., Schroeder, C., Mehta, A. D., \& Milham, M. P. (2018). On the importance of precise electrode placement for targeted transcranial electric stimulation. Neuroimage, 181, 560-567.

Ovadia-Caro, S., Khalil, A. A., Sehm, B., Villringer, A., Nikulin, V. V., \& Nazarova, M. (2019). Predicting the response to noninvasive brain stimulation in stroke. Frontiers in Neurology, 10,302

Pascual-Leone, A., Valls-Solé, J., Wassermann, E. M., \& Hallett, M. (1994). Responses to rapid-rate transcranial magnetic stimulation of the human motor cortex. Brain, 117(4), 847-858.

Peleman, K., Van Schuerbeek, P., Luypaert, R., Stadnik, T., De Raedt, R., De Mey, J., Bossuyt, A., \& Baeken, C. (2010). Using 3D-MRI to localize the dorsolateral prefrontal cortex in TMS research. The World Journal of Biological Psychiatry: The Offcial Journal of the World Federation of Societies of Biological Psychiatry, 11(2 Pt 2), 425-430.

Peters, M. D., Godfrey, C. M., Khalil, H., McInerney, P., Parker, D., \& Soares, C. B. (2015). Guidance for conducting systematic scoping reviews. International Journal of Evidence-based Healthcare, 13(3), 141-146.

Peters, J. C., Reithler, J., de Graaf, T. A., Schuhmann, T., Goebel, R., \& Sack, A. T. (2020). Concurrent human TMS-EEG-fMRI enables monitoring of oscillatory brain state-dependent gating of cortico-subcortical network activity. Communications Biology, 3(1), 40.

Polania, R., Nitsche, M. A., \& Ruff, C. C. (2018). Studying and modifying brain function with non-invasive brain stimulation. Nature Neuroscience, 21(2), 174-187.

Pommier, B., Vassal, F., Boutet, C., Jeannin, S., Peyron, R., \& Faillenot, I. (2017). Easy methods to make the neuronavigated targeting of DLPFC accurate and routinely accessible for rTMS. Neurophysiologie Clinique/Clinical Neurophysiology, 47(1), 35-46.

Ray, N. J., \& Strafella, A. P. (2012). The neurobiology and neural circuitry of cognitive changes in Parkinson's disease revealed by functional neuroimaging. Movement Disorders: Official Journal of the Movement Disorder Society, 27(12), 1484-1492.

Rektorova, I. (2019). Current treatment of behavioral and cognitive symptoms of Parkinson's disease. Parkinsonism \& Related Disorders, 59, 65-73.

Rich, T. L., Menk, J. S., Rudser, K. D., Chen, M., Meekins, G. D., Peña, E., Feyma, T., Bawroski, K., Bush, C., \& Gillick, B. T. (2017). Determining electrode placement for transcranial direct current stimulation: a comparison of EEG- versus TMS-guided methods. Clinical EEG and Neuroscience, 48(6), 367-375.

Richter, L., Neumann, G., Oung, S., Schweikard, A., \& Trillenberg, P. (2013). Optimal coil orientation for transcranial magnetic stimulation. PloS One, 8(4), e60358.

Ruffini, G., Wendling, F., Sanchez-Todo, R., \& Santarnecchi, E. (2018). Targeting brain networks with multichannel transcranial current stimulation (tCS). Current Opinion in Biomedical Engineering, 8, 70-77.

Rusjan, P. M., Barr, M. S., Farzan, F., Arenovich, T., Maller, J. J., Fitzgerald, P. B., \& Daskalakis, Z. J. (2010). Optimal transcranial magnetic stimulation coil placement for targeting the dorsolateral prefrontal cortex using novel magnetic resonance image-guided neuronavigation. Human Brain Mapping, 31(11), 1643-1652.

Salvador, R., Truong, D. Q., Bikson, M., Opitz, A., Dmochowski, J., \& Miranda, P. C. (2019). Role of computational modeling for dose determination. In Practical Guide to Transcranial Direct Current Stimulation (pp. 233-262). Springer, Cham.

Saturnino, G. B., Madsen, K. H., \& Thielscher, A. (2019). Electric field simulations for transcranial brain stimulation using FEM: an efficient implementation and error analysis. Journal of Neural Engineering, 16(6), 066032.

Seo, H., Kim, H. I., \& Jun, S. C. (2017). The effect of a transcranial channel as a skull/brain interface in high-definition transcranial direct current stimulation-a computational study. Scientific Reports, 7, 40612.

Smith, Y., Wichmann, T., Factor, S. A., \& DeLong, M. R. (2012). Parkinson's disease therapeutics: new developments and challenges since the introduction of levodopa. Neuropsychopharmacology, 37(1), 213-246. 
Spagnolo, F., Volonté, M. A., Fichera, M., Chieffo, R., Houdayer, E., Bianco, M., Coppi, E., Nuara, A., Straffi, L., Di Maggio, G., Ferrari, L., Dalla Libera, D., Velikova, S., Comi, G., Zangen, A., \& Leocani, L. (2014). Excitatory deep repetitive transcranial magnetic stimulation with $\mathrm{H}$-coil as add-on treatment of motor symptoms in Parkinson's disease: an open label, pilot study. Brain Stimulation, 7(2), 297-300.

Sparing, R., Hesse, M. D., \& Fink, G. R. (2010). Neuronavigation for transcranial magnetic stimulation (TMS): where we are and where we are going. Cortex, 1(46), 118-120.

Stenroos, M., \& Koponen, L. M. (2019). Real-time computation of the TMS-induced electric field in a realistic head model. NeuroImage, 203, 116159.

Syeda, F., Magsood, H., Lee, E. G., El-Gendy, A. A., Jiles, D. C., \& Hadimani, R. L. (2017). Effect of anatomical variability in brain on transcranial magnetic stimulation treatment. AIP Advances, 7(5), 056711.

Terranova, C., Rizzo, V., Cacciola, A., Chillemi, G., Calamuneri, A., Milardi, D., \& Quartarone, A. (2019). Is there a future for non-invasive brain stimulation as a therapeutic tool?. Frontiers in Neurology, 9, 1146.

Tessitore, A., Cirillo, M., \& De Micco, R. (2019). Functional connectivity signatures of Parkinson's disease. Journal of Parkinson's Disease, 9(4), 637-652.

Thirugnanasambandam, N., Grundey, J., Paulus, W., \& Nitsche, M. A. (2011). Dose-dependent nonlinear effect of L-DOPA on paired associative stimulation-induced neuroplasticity in humans. Journal of Neuroscience, 31(14), 5294-5299.

Thut, G., Bergmann, T. O., Fröhlich, F., Soekadar, S. R., Brittain, J. S., Valero-Cabré, A., Sack, A. T., Miniussi, C., Antal, A., Siebner, H. R., Ziemann, U., \& Herrmann, C. S. (2017). Guiding transcranial brain stimulation by EEG/MEG to interact with ongoing brain activity and associated functions: A position paper. Clinical Neurophysiology: Official Journal of the International Federation of Clinical Neurophysiology, 128(5), 843-857.
To, W. T., De Ridder, D., Hart Jr, J., \& Vanneste, S. (2018). Changing brain networks through non-invasive neuromodulation. Frontiers in Human Neuroscience, 12, 128.

Tricco, A. C., Lillie, E., Zarin, W., O’Brien, K. K., Colquhoun, H., Levac, D., Moher, D., Peters, M., Horsley, T., Weeks, L., Hempel, S., Akl, E. A., Chang, C., McGowan, J., Stewart, L., Hartling, L., Aldcroft, A., Wilson, M. G., Garritty, C., Lewin, S., ... Straus, S. E. (2018). PRISMA Extension for Scoping Reviews (PRISMA-ScR): Checklist and Explanation. Annals of Internal Medicine, 169(7), 467-473.

Udupa, K., \& Chen, R. (2013). Motor cortical plasticity in Parkinson's disease. Frontiers in Neurology, 4, 128.

Wang, J., Meng, H. J., Ji, G. J., Jing, Y., Wang, H. X., Deng, X. P., Feng, Z. J., Zhao, N., Zang, Y. F., \& Zhang, J. (2020). Finger tapping task activation vs. TMS hotspot: different locations and networks. Brain Topography, 33(1), 123-134.

Wei, X., Li, Y., Lu, M., Wang, J., \& Yi, G. (2017). Comprehensive survey on improved focality and penetration depth of transcranial magnetic stimulation employing multi-coil arrays. International Journal of Environmental Research and Public Health, 14(11), 1388.

Wolters, A. F., van de Weijer, S. C., Leentjens, A. F., Duits, A. A., Jacobs, H. I., \& Kuijf, M. L. (2019). Resting-state fMRI in Parkinson's disease patients with cognitive impairment: A meta-analysis. Parkinsonism \& Related Disorders, 62, 16-27.

Woods, A. J., Antal, A., Bikson, M., Boggio, P. S., Brunoni, A. R., Celnik, P., Cohen, L. G., Fregni, F., Herrmann, C. S., Kappenman, E. S., Knotkova, H., Liebetanz, D., Miniussi, C., Miranda, P. C., Paulus, W., Priori, A., Reato, D., Stagg, C., Wenderoth, N., \& Nitsche, M. A. (2016). A technical guide to tDCS, and related non-invasive brain stimulation tools. Clinical Neurophysiology: Official Journal of the International Federation of Clinical Neurophysiology, 127(2), 1031-1048. 